\title{
DEVELOPMENT OF AN ENERGY EFFICIENT HIGH TEMPERATURE NATURAL GAS FIRED FURNACE
}

\author{
Final Report \\ Dr. Mark G. Stevens \\ Dr. H. Kenneth Staffin
}

PROCEDYNE CORP.

11 Industrial Drive

New Brunswick, NJ 08901

Date Published - February 28, 2005

PREPARED FOR THE UNITED STATES

DEPARTMENT OF ENERGY

Under Contract Number

DE-FG36-00GO10517 


\section{ABSTRACT}

U.S. manufacturers have a strong interest in more energy efficient processes. Funded by Gas Research Institute Illinois, and subsequently by NJ Commission on Science and Technology; Procedyne Corp. has developed a heating concept demonstrated on a bench-scale test unit, to improve the capacity and the efficiency of the gas-fired retort furnaces used for commercial processing.

These furnaces consist of a retort and a gas-fired heating mantle. Combustion gas heats the retort when flowing through an annular area surrounding the retort. The objective is to improve the heat transfer to the retort and thereby increase the capacity and the efficiency of the furnace.

The design concept is designated the "Porous Wall Radiation Barrier" heating mantle. In this design, combustion gas flows through a porous wall surrounding the retort, transferring its heat to the porous wall, which then radiates heat energy to the retort.

Theoretical studies showed, operating above $1700^{\circ} \mathrm{F}\left(927^{\circ} \mathrm{C}\right)$ will transfer twice as much heat as a comparable electrically heated furnace. Experiments demonstrated that heat transfer rates of 1.8-2.4 times conventional gas fired mantles are achievable in the temperature range of $1600-2350^{\circ} \mathrm{F}\left(1582^{\circ} \mathrm{C}-1288^{\circ} \mathrm{C}\right)$.

A potential for annual U.S. energy savings of $\$ 997$ million, and $65-75 \%$ reduction in environmental pollutant emission have been identified.

The focus of this program was to design, construct and operate a prototype retort furnace heated by a PWRB mantle to demonstrate its performance benefits and the feasibility of the mechanical design as a basis for a scale-up to larger commercial furnaces.

The furnace designed and constructed under this program achieved the objectives of the program. 


\section{$1.0 \quad$ INTRODUCTION}

\subsection{Background Information}

The gas-fired heating mantle, which constitutes the energy source for indirectly heating retort furnaces, is an important processing element in heat-treating and metal processing furnaces, and inorganic chemical reactors. These types of furnaces and reactors are being used extensively in the heat-treating, metal processing and inorganic chemical industries.

The current state-of-the art technology in the gas-fired heating mantle contains some important deficiencies which limit the number of successful commercial applications. If current technology in gasfired mantles were advanced, particularly in the higher temperature range, the number of heating mantles in commercial applications would increase significantly, thereby, increasing the use of natural gas for the indirect heating of furnaces and reactors. Limitations in current state-of-the art technology is primarily associated with the heat transfer rate performance.

\subsubsection{Heat Transfer Limitation}

The heating mantle surrounding a furnace retort vessel involves high rate heating in a small space geometry with controlled position of flames to avoid damage to the furnace retort vessel - typically fabricated from high temperature alloy materials.

In this type of situation, the heat transfer mechanism consists primarily of convective heat transfer from the combustion gases to the heating mantle wall and the retort vessel outer wall, and radiant heat transfer from the heating mantle wall to the retort vessel outer wall, and radiant heat transfer from the heating mantle wall to the retort vessel wall. Momentum input into flames is severely limited by burner design which coupled with typical mantle geometric limitations, makes it difficult to achieve high convective heat transfer rates, at the gas velocities encountered in a heating mantle annulus. In addition, when natural gas is the energy supply, the high temperature gases are not luminescent so there is not a high rate radiant heat transfer directly from the heating gases to the walls of the annulus.

Some efforts to increase the connective heat transfer coefficients to the retort wall and the heating mantle inside wall have achieved increased heat transfer rates using geometric baffles in the annulus space to cause gas phase turbulence and kinetic energy transfer. The most recent example of this is the Jet fire (1) geometric baffling concept.

When heating temperatures are above $1600^{\circ} \mathrm{F}\left(871^{\circ} \mathrm{C}\right)$, the radiation heat transfer rates from the heating mantle wall to the furnace retort or reactor are sufficiently high to satisfy most process specifications and requirements. The heat transfer problem is one of maintaining the heat transfer rates from the heating gas to the furnace mantle wall via convection - this is usually the rate limiting heat transfer rate in these applications. 


\subsubsection{Porous Wall Radiation Barrier (PWRB) Concept}

Under a cost sharing contract funded by the Gas Research Institute (GRI) and Procedyne Corp. No. 5087235-1537, Development of an Advanced Gas-Fired Heating Mantle, the concept of a Porous Wall Radiation Barrier (PWRB) heating mantle was conceived and patented under U.S. Patent No. 4,957,431 granted September 18, 1990.

\section{i. PWRB Concept}

The PWRB concept for heating retorts is illustrated in Figure 1. The cylindrical retort contains the parts or powder being heated in the retort in a typical application. The retort is surrounded by a concentric cylindrical porous wall forming an inner annulus space between the inside porous wall and the outside wall of the retort. It also forms an outside annulus space between the outside porous wall and the inner wall of the insulation cylindrical wall formed by the insulation mounted on the inside of the furnace steel shell. The inner annulus space and the outer annulus space are shown in Figure 1.

The burner is shown in the lower section of the furnace firing into a lower annulus. The burner discharges its combustion gas into the lower annulus, which discharges its combustion gases into the inner annulus. The burner discharge is tangential to the lower annulus to establish a uniform flow in the lower annulus chamber and into the inner annulus.

With the inner annulus sealed at the top and the bottom from the outer annulus, the combustion gases flow from the inner annulus through the porous wall into the outer annulus and out through the combustion gas discharge.

\section{ii. PWRB Models}

During the original GRI/Procedyne development contract, two mathematical models representing the PWRB concept were developed. The two models were based on two different assumptions with respect to the flow configuration of combustion gases flowing through the porous wall. The two assumptions were significantly different and yielded two different predictions of heat transfer behavior. The two models are illustrated in Figure 2. "Finite Area", Figure 2a, is a schematic representation of gas flow through a porous wall for heating a retort, Figure $2 \mathrm{~b}$ illustrates temperature profiles predicted by the "Infinite Area" model and Figure $2 c$ those predicted by the "Finite Area" model.

The foam model assumes a porous slab to be constructed of very small spherical particles or cells having so large an area to be considered infinity area for all practical purposes. According to the model, the hot gases penetrating the inside wall of the porous slab are in contact with infinite heat transfer area, and thus reach thermal equilibrium with the individual particles or cells within an infinitesimal penetration, so that the inside wall of the porous slab facing the retort wall operates at the temperature of the high temperature gases, $\mathrm{T}_{\text {gi }}$ in Figure $2 \mathrm{~b}$. At high operating temperatures, $1500^{\circ} \mathrm{F}$ to $2400^{\circ} \mathrm{F}\left(816^{\circ} \mathrm{C}-1316^{\circ} \mathrm{C}\right)$, the inside wall of the porous slab radiates to the retort wall, with an extremely high heat 
transfer coefficient. The temperature of the combustion gases passing through the porous slab (equal to the slab temperature at any depth of penetration) decreases until the gas discharges at its lowest temperature, $\mathrm{T}_{\mathrm{go}}$ in Figure $2 \mathrm{~b}$. In a hypothetical installation, the hot combustion gases pass up through the annulus between the retort wall and the porous slab, transferring heat to each of these surfaces by convection. The gases then pass through the porous slab flowing away from the retort, bringing the inner surface temperature of the porous slab to the temperature of the hot gases through continued convective heat transfer with infinite heat transfer area. Finally the inner surface of the porous slab transfers heat to the retort wall by radiation heat transfer.

Heat transfer coefficients estimated by the Infinite Areas model were extremely high, well in excess of $100 \mathrm{BTU} / \mathrm{hr} . \mathrm{ft}^{2}{ }^{\circ} \mathrm{F}$. It was also predicted that energy efficiency would be enhanced due to lowering of the gas discharge temperature by the porous slab.

The Finite Area model assumed that the porous material was a slab drilled with many small diameter holes, the holes being tangent to each other. Thus, the inside wall of the porous slab, facing the retort, has a finite area; the area of the material not removed by the holes. According to this model, the hot combustion gases enter the multitude of parallel tubes formed by the holes and transfer heat, predominantly by convection, to the inside walls of the tubes, as the gases flow through the porous slab from the inside wall nearest the retort to the outer wall. Since the hot gases heat the porous slab while passing through tubes, the temperature of the porous slab increases with the depth of penetration of the hot gases to a maximum. The combustion gas exits the outside wall at an intermediate temperature, equal to the slab temperature at the outside wall; $\mathrm{T}_{\mathrm{w}}$ (outside wall) $=\mathrm{T}_{\mathrm{go}}$ in Figure $2 \mathrm{c}$. The inside wall temperature of the porous slab is, in this case, considerably lower than the temperature of the combustion gases entering the porous slab, i.e., $T_{w}$ (inside wall) $<T_{g i}$ in Figure 2c.

\subsubsection{Test Verification of Computer Models}

In 1991 as part of a cost sharing contract by GRI and Procedyne, a test study was performed at Stevens Institute of Technology (SIT), Hoboken, New Jersey to experimentally evaluate the validity of the PWRB heating mantle mathematical models with respect to heat transfer rate behavior.

Under simulated test conditions, the results of this study were strongly positive. In the temperature range of $750^{\circ} \mathrm{F}$ to $1500^{\circ} \mathrm{F}\left(399^{\circ} \mathrm{C}\right.$ to $\left.816^{\circ} \mathrm{C}\right)$, the PWRB concept exhibited heat transfer rates 1.8 times rates topically achieved with conventional jacket type heating mantles. In the temperature range of $1500^{\circ} \mathrm{F}$ to $2100^{\circ} \mathrm{F}\left(816^{\circ} \mathrm{C}\right.$ to $\left.1149^{\circ} \mathrm{C}\right)$, this rate factor increased from 1.8 to a level of 4.0 at $2100^{\circ} \mathrm{C}\left(1149^{\circ} \mathrm{C}\right)$.

In 1998, SIT and Procedyne collaborated in a program funded by the New Jersey Commission of Science and Technology having as its objective to simulate a retort furnace in a test apparatus, for both a flat porous plate and a cylindrical porous plate retort furnace geometry, to obtain design information to permit construction and test operation of a prototype retort furnace based on the PWRB heating mantle principle.

Based on the above background, the US Department of Energy (DOE) with cost sharing by Procedyne Corp. approved DOE Contract No. DE-FG36-00G0 10517 to advance this development to the point where 
a commercial retort furnace, capable of providing the energy utilization benefits suggested by prior work, could be introduced to some important elevated temperature thermal processing industries.

This document is the Final Report of this program entitled "Development of an Energy Efficient High Temperature Natural Gas Fired Furnace.

\subsection{OVERALL PROGRAM OBJECTIVE}

The major focus of this developmental project was to design, construct, and test a prototype furnace, based on the porous wall concept previously developed, to evaluate construction materials, construction methods, and heat transfer characteristics. The prototype was then field tested in a heat-treating application to gather data. The objectives of the project were successfully accomplished and are presented in this report. 

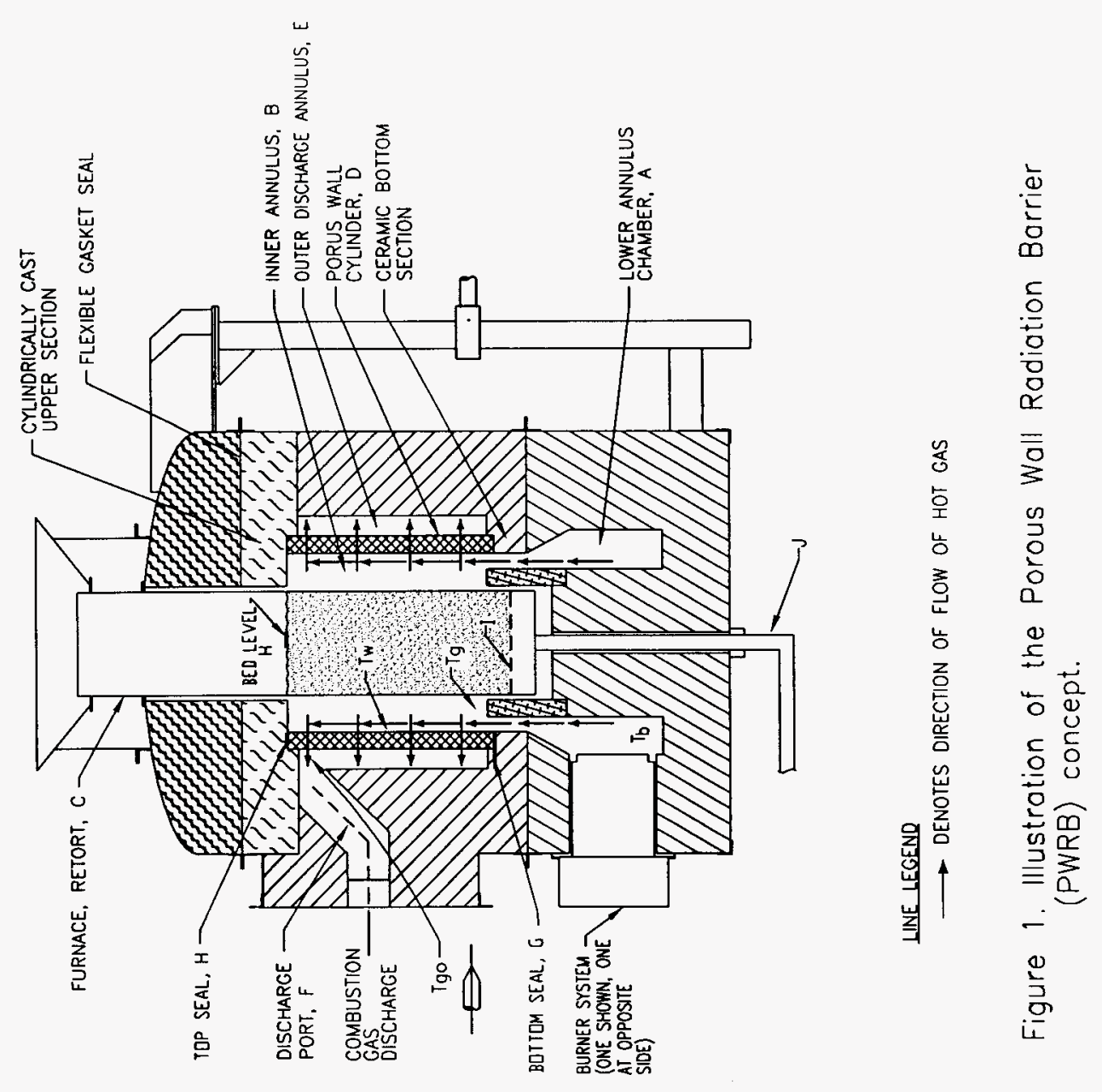
$2 a$.

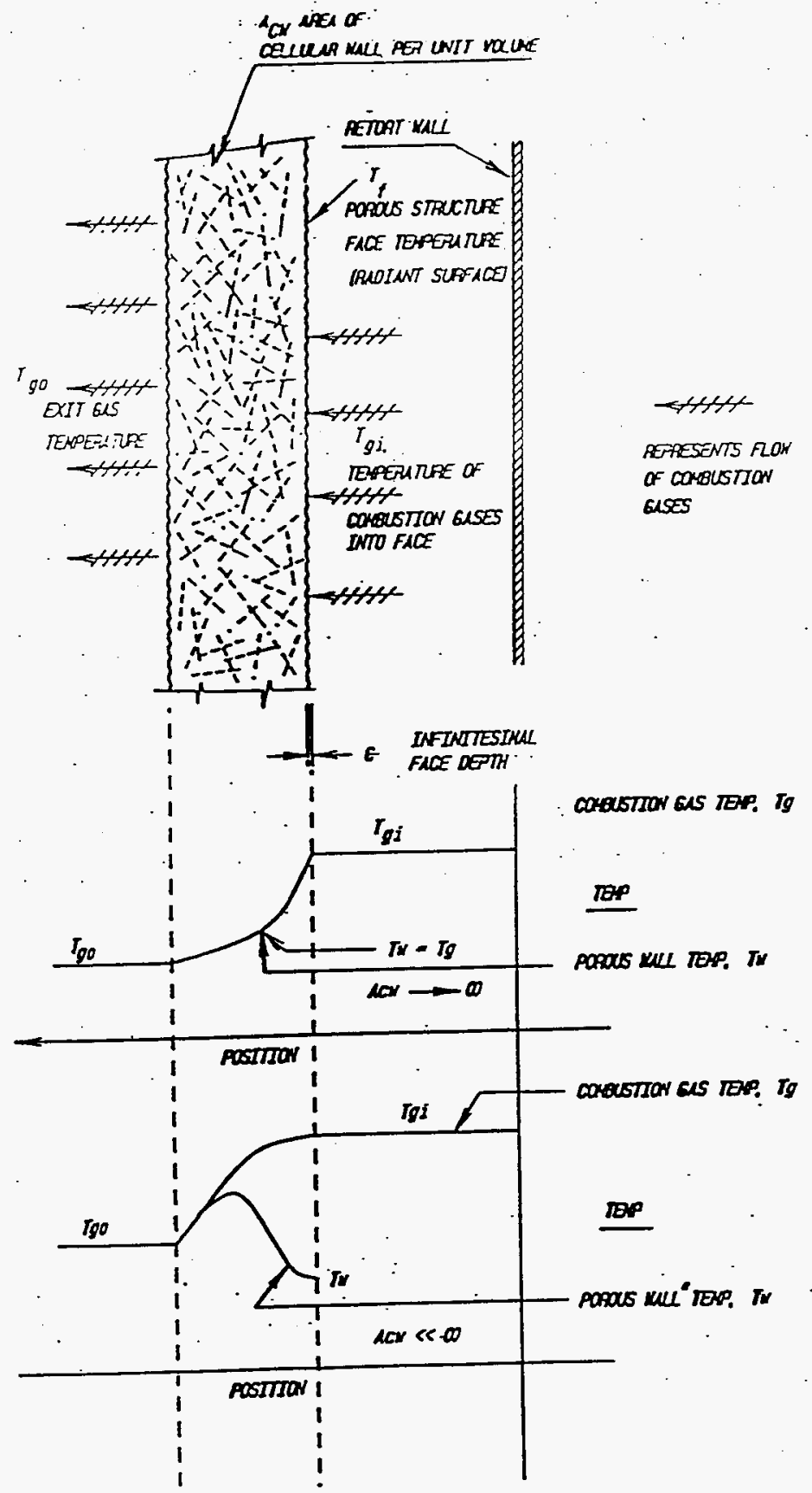

Figure 2. Illustration of the two proposed models for heat transfer in a PWRB heating mantle

a) Schematic of a PWRB system for heating a retort

b) Illustration of the finite surface (tube bundle) model

c) Illustration of the infinite surface (small particle) model 


\subsection{THE PROGRAM}

\subsection{Furnace Design Basis}

The prototype furnace selected to evaluate the heat transfer behavior of the porous wall concept was a vertical cylinder retort furnace as shown in Figure 1. The application chosen for this furnace was a fluid bed heat-treating furnace with a maximum operating temperature capability of $2200^{\circ} \mathrm{F}\left(1204^{\circ} \mathrm{C}\right)$ in the fluidized solids bed.

Referring to Figure 1 the burner shown is a positive mix burner, which tangentially discharges its high temperature combustion gases into lower annulus chamber $\mathrm{A}$ from which they spiral up into the inner annulus chamber $\mathrm{B}$ between the furnace retort $\mathrm{C}$ and the porous wall cylinder $\mathrm{D}$. These flowing gases contact the furnace retort and flow uniformly through the wall of the porous wall cylinder $\mathrm{D}$ into the discharge annulus $\mathrm{E}$ and out through discharge port $\mathrm{F}$.

To insure that the combustion gases flow uniformly through porous cylinder $\mathrm{D}$ at all levels from the top of the porous cylinder to the bottom, it is essential that the cylinder is well sealed at the top and bottom to the furnace insulation at $\mathrm{G}$ and $\mathrm{H}$ respectively.

In addition, it is essential that the size of the annulus space between the retort wall and the inner wall of the porous wall be large enough that the pressure drop of the flowing high temperature combustion gases in the vertical flow direction is sufficiently low that the flow through the porous wall at its lower elevation is not greater than at its higher elevation due to this pressure drop.

And finally, there must be sufficient pressure drop of the flowing high temperature combustion gases from the inner annulus space B through the porous wall D, to the discharge annulus E, to achieve uniform flow of this gas phase through the porous wall $\mathrm{D}$.

Referring to Figure 1, it was concluded that for the intended application of this furnace, the retort $G$, would be 10 -inch diameter inside working volume with fluidized solids bed depth of 24.0 inches shown as point $\mathrm{H}$ in Figure 1.

It was further concluded that the design operating temperature of the fluidized solids bed was $2200^{\circ} \mathrm{F}$ $\left(1204^{\circ} \mathrm{C}\right)$, which would permit using the furnace in a number of important commercial heat treating processes.

The retort $\mathrm{G}$, to operate, as a fluid bed furnace was equipped with a distributor plate I and a fluidizing gas feed line $\mathrm{J}$. 
With the above furnace as the design basis, the operating parameters for the planned furnace were designated as shown in Table 3.1-1.

TABLE 3.1-1

Test Furnace Operating Parameters

\begin{tabular}{|c|c|c|}
\hline \multicolumn{2}{|l|}{ Furnace Position } & $\begin{array}{c}\text { Design Basis Operating } \\
\text { Temperature }{ }^{\circ} \mathrm{F}\left({ }^{\circ} \mathrm{C}\right)\end{array}$ \\
\hline \multicolumn{2}{|l|}{$\begin{array}{l}\text { Burner Combustion Gas } \\
\text { Discharge: }\end{array}$} & \\
\hline Lower Annulus Chamber, & $\mathrm{A}$ & $2400 \max (1315.6)$ \\
\hline Inner Annulus Chamber, & $\mathrm{B}$ & $2200 \max (1204.4)$ \\
\hline Porous Wall Cylinder, & $\mathrm{D}$ & $2400 \max (1315.6)$ \\
\hline Discharge Annulus, & $\mathrm{E}$ & $2300 \max (1260.0)$ \\
\hline Discharge Port, & $\mathrm{F}$ & $2400 \max (1315.6)$ \\
\hline Retort Fluidized Bed, & $\mathrm{H}$ & $2200 \max (1204.4)$ \\
\hline
\end{tabular}

\subsection{Selection of Porous Wall Material}

The most important element in a heating mantle based on the porous wall concept is the cylindrical porous wall cylinder. The inside cylindrical face is the radiation surface that provides for most of the heat transfer to the retort. This face temperature is uniform provided the flow of high temperature combustion gas is flowing uniformly into the face and there is no significant flow that can bypass the cylinder.

In addition to sufficient uniform flow entering the face there must be a sufficiently fine uniform porosity to provide sufficient wall area of the internal flow paths to achieve a high rate of heat transfer from the flowing gas to the pore walls which in turn radiates from the inside surface to the retort.

To prevent by-passing, the top and bottom ends of the cylinder are compressed between a top face of ceramic and a bottom face of ceramic which are part of the insulation structure of the heating mantle. A gasket at each end of the porous wall cylinder edge face seals the two surfaces against gas flow, $\mathrm{G}$ and $\mathrm{H}$ in Figure 1.

To meet the requirements of the porous wall cylinder, its material of construction must withstand the high temperature combustion gases without deterioration, the compressive force required to achieve sufficient sealing of the gasketed seals and it must also have a sufficiently fine porosity to provide sufficient internal path surface area at the internal surface of the cylinder to operate at a temperature close to the temperature of the combustion gases entering its surface. It must also be capable of being properly joined with suitable high temperature cement so that large porous cylinders can be constructed of pieces "keyed and cemented together." 
Due to the critical nature of selecting a suitable material of construction of this element, initial efforts of this program were focused on making the selection.

Based on a detailed review of prior development work on the PWRB heating mantle program, it was concluded that silicon carbide was the most suitable material of construction of the porous wall cylinder. The remaining effort was to find silicon carbide material of proper porosity and physical form to meet the design requirements of a furnace-heating mantle.

Additional requirements of this material became apparent during the initial design considerations as follows:

- It was noted that the pressure drop across the gasketed seals at the top and bottom of the porous cylinder, was equal to the pressure drop of the flowing combustion gases through the porous wall cylinder.

Therefore, increasing the pressure drop across the porous wall to achieve increasing uniformity of flow through the cylinder wall had to be balanced against the increasing demand of the gasket seals at the top and bottom of the porous wall cylinder.

- Increasing the porosity of the porous wall to reduce pressure drop through the walls results in reduced wall area of the interstices which reduces the heat transfer rates from the combustion gases to the porous wall which reduces the inside face temperature of the porous wall cylinder which reduces the rate of radiant heat transfer to the retort.

- Since the porous wall of a commercial furnace would typically have to be constructed of a number of suitably shaped prices of porous silicon carbide material, it is necessary to join, or cement the pieces together. The material chosen for the porous cylinder must be capable of joining by a technique that would withstand the rigors of the porous wall cylinder in the PWRB mantle.

Following a significant effort involving contact with vendors supplying silicon carbide porous slab and cylinder materials, the following was chosen as the material of construction: 


\section{POROUS WALL MATERIAL SPECIFICATION}

\section{Material of Construction: \\ Material Structure}

Air Flow Pressure Drop:

Maximum Operating

Temperature:

Dimensional Requirements:
Silicon Carbide material

Vesuvius 20ppi OBSiC

0.5 psig $/ 250$ Acfm @2200 $\mathrm{F}$

$\left(1204^{\circ} \mathrm{C}\right)$

$2400^{\circ} \mathrm{F}\left(1316^{\circ}\right)$
Cylinder ID:
14 inches, Tolerance $+1 / 8 /-0$
Cylinder OD:
18 inches, Tolerance $+1 / 8 /-0$
Cylinder Length:
24 inches fluid bed level

Cylindrical Construction:

Cylinder height met by cementing cylinders 2 inches in height on top of each other, i.e., 12 cylinders to make up the 24 inch required height. An alternate material was tested, 45 ppiOBSiC but war rejected because the pressure drop through the material was considered to high.

\subsection{Engineering Design of Furnace}

\subsubsection{Heating Mantle Shell}

The PWRB heating mantle is the fundamental element of the retort furnace of interest in this program.

The conventional aspects of the PWRB heating mantle design was that it would have a typical steel shell which contained the insulation of shell and the mounting of the burner system with the insulated passageways for the combustion gases to be fed to the heat transfer annulus surrounding the retort being heated.

The shell design for this prototype furnace is shown in Drawing No. D - 17679, Rev D, in Appendix IV of this report. The shell is constructed of steel and contains the required support detail required of the mantle design. The natural gas burner mounting plate is shown in this drawing as Item No. 7. 
The natural gas burner is mounted on the shell in a position to discharge its high temperature combustion gas tangentially to the circular lower annulus chamber shown schematically in Figure 1.

The cover of the shell is a 10 gage steel dished head. The cover is insulated with Kaowood fiber insulation, and is equipped with an exhaust pipe assembly to discharge fluidization gases.

\subsubsection{Heating Mantle Internal Passages}

The design of the internals of the PWRB mantle has as its requirement to direct the burner high temperature combustion gases to the passages that accomplish the transfer of heat from the gases to the retort, and to provide the necessary insulation to keep the steel mantle shell at a temperature below $140^{\circ} \mathrm{F}\left(60^{\circ} \mathrm{C}\right)$ to control heat losses and for operator protection.

The design for the PWRB heating mantle for this program is shown in Drawing No. D-17664, Rev. $\mathrm{C}$ in Appendix IV. The steel mantle shell is insulated essentially throughout with 12 inches of insulating modules $9.3 \mathrm{lb} / \mathrm{ft}^{3}$ density around the heating section, to meet the needs for controlled heat losses and operator protection.

The positive mix burner is mounted on the tangential port in the lower one third of the furnace shown in Drawing No. D-17679, Rev. D, Item 7. This port is rectangular in cross sectional shape.

This entire lower one-third section of the furnace, from the lower flange to the bottom, is filled with two layers of castible insulation. The outside layer is 6 inches thick and the inside layer is 6 inches thick. The inside layer is cast to form the lower annulus chamber, A, to which the burner directs the high temperature combustion gases are directed through the rectangular feed port and tangentially enters the lower annulus chamber as shown schematically in Figure 1 . The lower annulus chamber is formed with LW $26,70 \mathrm{lbs} / \mathrm{ft}^{3}$ castible insulation having a maximum operating temperature of $2400 \mathrm{~F}\left(1316^{\circ} \mathrm{C}\right)$. Surrounding the castible forming the lower annulus chamber is a lighter weight castible, which extends out to the furnace shell. This castible is $\mathrm{LW} 20,55 \mathrm{lb} / \mathrm{ft}^{3}$.

The upper part of the castible forming the lower annulus chamber at the flange line of the lower section is the base for the seal of the porous wall cylinder. A one-quarter inch Durablanket forms the gasket between the lower furnace section and the middle furnace section, and also forms the gasket for the porous wall cylinder sitting on this section.

The high temperature combustion gases flow into the inner annulus, pass through the porous wall cylinder to the outer discharge annulus. The outer wall of the outer discharge annulus is $2300^{\circ} \mathrm{F}$ $\left(1260^{\circ} \mathrm{C}\right)$ and insulated by Insulating Module $12 " \times 12 " \times 12 ", 9.3 \mathrm{lb}$. density.

The top section of the furnace is insulated with a 2 inch layer of Durabond, and four layers of Durablanket, 2" thick, $6 \mathrm{lbs}$ per cubic inch density. The 2 inch layer of Duraboard in the top cover rests on the top edge of the porous wall cylinder, which seals the top edge of the porous wall cylinder and prevent leakage of the combustion gas around the porous wall cylinder. 
From the outer discharge annulus, the combustion gases pass through a port in the 12 " $\mathrm{x} 12$ " $\mathrm{x} 12$ " insulating modules to the collection chute which then feeds the combustion gas discharge to the atmosphere.

\subsubsection{The Furnace Retort}

The PWRB heating mantle could be used to provide indirect heating of any type retort or reactor. For this program, the mantle was applied to heat a fluid bed heat treating furnace retort.

The retort construction, as shown in Drawing No. D-17664, Rev. C was fabricated of Inconel 601 metal and equipped with a Procedyne Screw type distributor plate. The retort is designed and equipped as a fluid bed furnace.

The retort is designed for operation with the fluidized bed at $2200^{\circ} \mathrm{F}\left(1204^{\circ} \mathrm{C}\right)$. The retort is equipped with a plenum chamber and a fluidizing gas line which passes through the shell of the furnace through a sealing gland to prevent combustion gas leakage to the atmosphere.

The retort is equipped with a cover, which contains a fluidizing offgas port.

\subsubsection{Process Control and Parameter Monitoring}

i. Furnace Control Systems (Refer to Figure 3)

Temperature control of the furnace was based on controlling the fluid bed temperature in the retort vessel, TE-6, shown in Figure 3. This thermocouple sensor in the fluid bed provided the temperature to a temperature controller which controlled the temperature by adjusting the flow rate of natural gas to the burner of the lower annulus chamber, A. The burner control system then adjusted the combustion airflow rate by ratio control. The combustion gases were directed as shown to inner annulus B which adjusted the temperature of the fluid bed medium in the retort.

To protect the furnace retort against the possibility of over temperature of the combustion gases leaving the lower annulus $\mathrm{A}$, and entering inner annulus $\mathrm{B}$ activates a high temperature protection controller which shuts down the flow of natural gas if the temperature exceeds $2200^{\circ} \mathrm{F}$.

The flow of air to the fluid bed medium was controlled and monitored by flow indicator FI10 and a flow meter. Loss of air supply and/or low flow of this fluidizing air also shutdown natural gas supply to the furnace burner system to avoid overheating the furnace heating chambers. 
ii. Temperature Monitoring (Refer to Figure 3)

The temperatures at various points in the furnace were monitored to assist in monitoring the performance of the furnace and to verify design parameters.

These Temperature points were as follows:

\section{TABLE 3.3.4-1}

Temperature Monitoring

\begin{tabular}{cl} 
Sensing Element & Sensor Location \\
\cline { 2 - 3 } TE-1 & Entering inner annulus B \\
TE-2 & Inner Annulus, center \\
TE-4 & Discharging Combustion Gas \\
TE-5 & Retort fluid bed low \\
TE-6 & Retort fluid bed high \\
TE-9 & Porous wall cylinder/discharge side
\end{tabular}

\subsection{Test Operation of the Furnaces}

The next phase of the program was to start up and test-operate the furnace.

The primary objectives of the test operation was to determine heating rate capacity of the PWRB mantle, the efficiency of the heating mantle, the uniformity of heating, and the maintenance performance.

\subsubsection{Start up Procedure}

i. Initial Startup

With the significant amount of cast refractory in the PWRB furnace, the initial heating was carefully performed to assure drying of the refractory without inducing cracking.

The furnace lower annulus chamber was heated to $300^{\circ} \mathrm{F}\left(149^{\circ} \mathrm{C}\right)$ over a period of 2.0 hours, then held at this temperature for 2.0 hours. The temperature at this point was then raised $100^{\circ} \mathrm{F}$ $\left(55.6^{\circ} \mathrm{C}\right)$ every 2.0 and held for 2.0 hours at each temperature.

When the temperature in the lower annulus chamber reached $2200^{\circ} \mathrm{F}\left(1204^{\circ} \mathrm{C}\right)$ and held for 4.0 hours, it was concluded that the castible refractory was dry and cured.

Nothing unusual occurred during this phase of the startup. 


\section{ii. Operation}

The PWRB furnace was installed in New Brunswick, New Jersey in the Heat Treating operation of Fluidaire Cleaning System Inc.: a joint venture corporation of Procedyne and Schwing Fluid Technik GmbH, a German company with its commercial focus on contract cleaning of metal dies and parts for the plastics processing industry and heat-treating of parts for manufacturing companies.

The PWRB was installed adjacent to a line of fluid bed heat-treating furnaces and support equipment.

The installation is shown in Photographs in Appendix I including photographs of internal parts and the furnace in operation.

The furnace PWRB mantle was operated at temperatures as high as $2120^{\circ}\left(1160^{\circ} \mathrm{C}\right)$ during the operating periods.

\subsubsection{Operating Performance}

\section{i. Heating Rate Performance}

The transient and steady state heating rate performance was determined by controlling the burner discharge temperatures at a specifically chosen high temperature, and monitoring the response of the furnace. This characterized the transient rate performance of the PWRB mantle. The transient state is an important characteristic for heat-treating applications where ambient temperature loads of parts are typically fed to the furnace on a timed cycle. When the load enters the furnace the temperature inside the furnace drops as it starts heating the parts. The time elapsed until the furnace is returned to required operating temperature is referred to as the "recovery time". The transient response of the furnace is the performance of the furnace with respect to recovery time.

The heating rate was determined from an initial starting temperature, by starting the burners system and setting the controller for a constant heating rate and combustion gas temperature, by setting and controlling the natural gas flow rate to the burner and then controlling the air rate to the burner at a desired temperature well above $t_{0}$. The temperatures at the various locations in the heating mantle and the fluid bed retort were then monitored as the heating mantle and fluid bed in the retort were heated up, i.e., the transient period. 

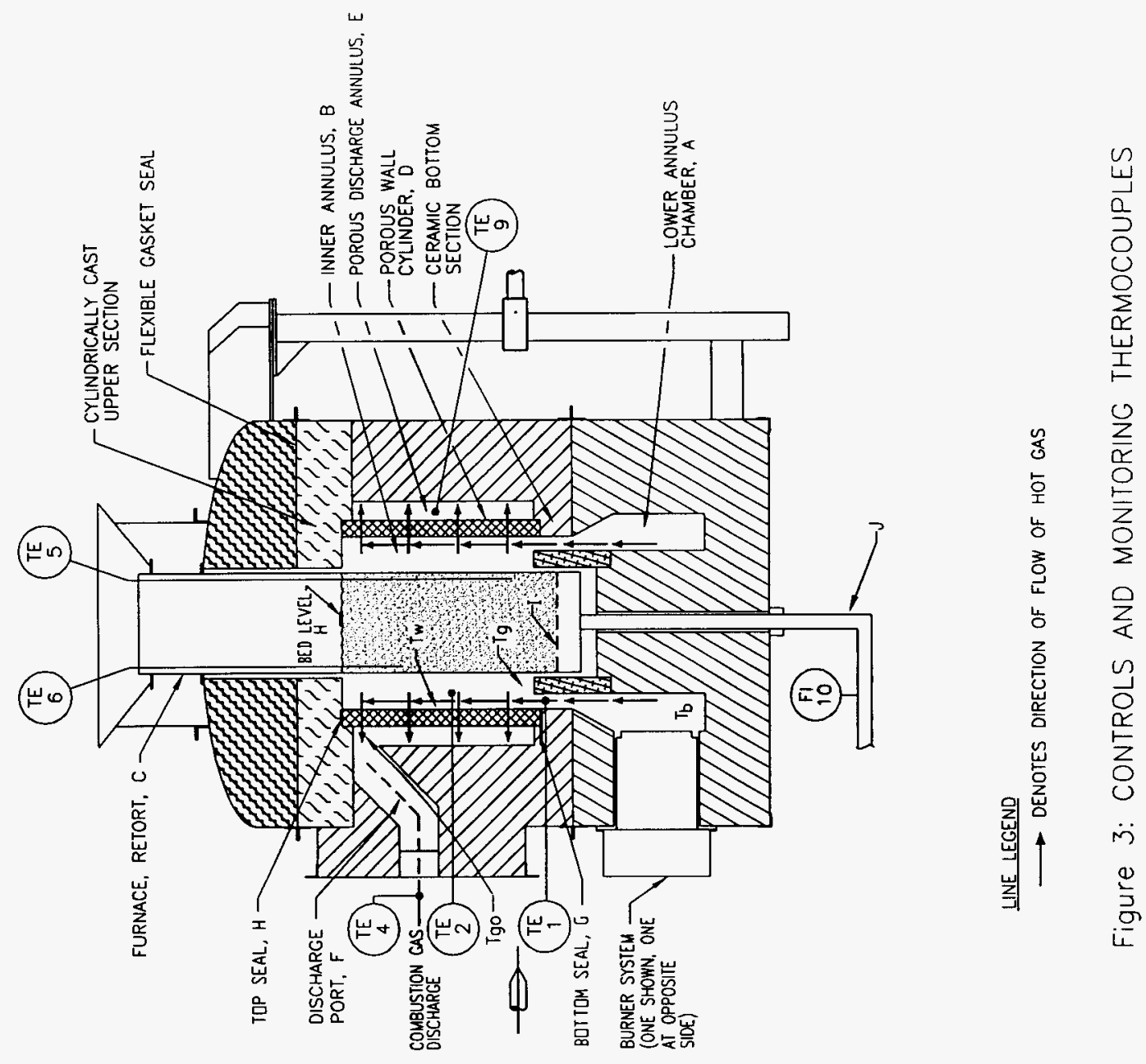
The temperatures were then monitored when the system reached its steady state levels and the system was operated under steady state conditions for at least one-quarter hour before the test run was considered complete.

The performance of the PWRB heating mantle was compared to the typical performance of a similar furnace heated by a heating mantle with a more conventional natural gas fired heating mantle and then with an electrically heated furnace with respect to typical heating capacity.

The curves shown in Figure 4 summarize the conclusions of the comparative tests. The data points for the PWRB heating mantle are given in Appendix II. The information for the comparative curves for conventional natural gas heated furnaces and the two major types of electrically heated furnaces are based on commercial experience with Procedyne manufactured heating mantle retort furnaces.

\subsubsection{Comparison with Conventional Heating Mantles}

\section{i. Conventional Natural Gas Fired Heating Mantles}

Referring to the graphs in Figure 4, the heat-up rate curve for the PWRB mantle heated furnace had an extremely high heat-up rate between $752^{\circ} \mathrm{F}$ and $1652^{\circ} \mathrm{F}\left(400^{\circ} \mathrm{C}\right.$ and $900^{\circ} \mathrm{C}$ ). This performance confirms the data previously obtained that indicated the heat transfer coefficient above $204^{\circ} \mathrm{F}\left(400^{\circ} \mathrm{C}\right)$ is very favorable because the radiation heat transfer component increases and becomes dominant.

Procedyne limits the temperature of the alloy retort vessel to $2048^{\circ} \mathrm{F}\left(1120^{\circ} \mathrm{C}\right)$ so the control systems are reducing the heat-up rate shown in Figure 5 as the bed temperature approaches $2102^{\circ} \mathrm{F}\left(1150^{\circ} \mathrm{C}\right)$. As a result of heating uniformity of the PWRB mantle, the furnace was operated at various periods at a temperature of $2120^{\circ} \mathrm{F}\left(1160^{\circ} \mathrm{C}\right)$.

In studying the comparison with a conventional natural gas fired heating mantle, as shown in Figure 4, the performance of the PWRB mantle is very close to a conventional mantle at fluid bed operating temperatures less than $752^{\circ} \mathrm{F}\left(400^{\circ} \mathrm{C}\right)$. The heating rate above this temperature of the PWRB mantle increase well above the conventional furnace mantle until the temperature control system starts limiting the rate to avoid an overshoot above $2120^{\circ} \mathrm{F}$ $\left(1160^{\circ} \mathrm{C}\right)$ the maximum operating temperature. In this furnace, for the heat-up of the furnace to $1832^{\circ} \mathrm{F}\left(1,000^{\circ} \mathrm{C}\right)$, the PWRB furnace was faster than a comparable conventionally heating mantle to this temperature by a factor of approximately 2.5 . This result is consistent with prior testing of the PWRB mantle, which showed even larger differences at the higher temperatures.

ii. Electrically Heated Mantles

Referring to the graphs in Figure 4, the heat-up rate curve for the PWRB Mantle was compared with two different types of electrical heating mantles that Procedyne has 
experience with due to being a supplier of these types of electrical heating mantles - the first being the direct contact band heaters, and second being the rod overbend heaters.

The electrical band heaters are limited to lower temperatures by their suppliers so this comparison was only made to a temperature of $860^{\circ} \mathrm{F}\left(460^{\circ} \mathrm{C}\right)$. The results of this comparison in Figure 4 , the electrical band heaters are faster heat-up at $572^{\circ} \mathrm{F}\left(300^{\circ} \mathrm{C}\right)$ temperature by a factor of approximately 1.1 but by $752^{\circ} \mathrm{F}\left(400^{\circ} \mathrm{C}\right)$, the PWRB mantle is ahead in heat-up rate to temperatures above approximately $707^{\circ} \mathrm{F}\left(375^{\circ} \mathrm{C}\right)$. Referring to Figure 4 , the fluid bed temperature was limited to $896^{\circ} \mathrm{F}\left(480^{\circ} \mathrm{C}\right)$.

Comparing the heat-up rate to $1472^{\circ} \mathrm{F}\left(800^{\circ} \mathrm{C}\right)$ the $\mathrm{PWRB}$ Mantle is capable of heating the furnace in shorter time by a factor of 1.5 .

iii. Temperature Uniformity

The internal geometry of the porous wall heating mantle provides very uniform heating of the retort vessel. The pressure differential across the porous wall is sufficient to provide a uniform temperature in inner annulus B. In a conventional natural gas fired heating mantle the high temperature combustion gases typically enter at the bottom of the mantle and leave at the top of the mantle. There is a differential temperature from the bottom of the heating annulus to the top of $90^{\circ} \mathrm{F}$ to $180^{\circ} \mathrm{F}\left(50^{\circ} \mathrm{C}\right.$ to $\left.100^{\circ} \mathrm{C}\right)$ in high temperature retort furnaces. With the PWRB mantle, the flow of high temperature combustion gas is through the porous wall radially away from the furnace retort. The temperature in the inner annulus B shows very little gradient from the lowest part of the heating annulus to the upper part. Therefore the furnace retort vessel is subject to very uniform temperature at its outside surface, which results in at higher temperature difference for that transfer to and through the vessel wall, and a significantly reduced thermal stress on the vessel wall.

A fluid bed furnace inherently provides excellent temperature uniformity in the fluidized solids medium but the temperature differences encountered in this test furnace over the 24 inch height of the fluidized bed were typically $\pm 3.6^{\circ} \mathrm{F}\left( \pm 2^{\circ} \mathrm{C}\right)$ which is half the variation typically encountered for this type furnace.

iv. Summary of Operating Performance

The test operation clearly demonstrated that the heat-up rate of the PWRB mantle was achieving the benefit forecasted by the computer models and the bench scale test programs, which preceded this demonstration program. The furnace design concept applied in this program appeared sound. The remaining two issues of importance were the maintenance performance of the design and the cost of the furnace design relative to alternative available heating mantles for retort performances. 


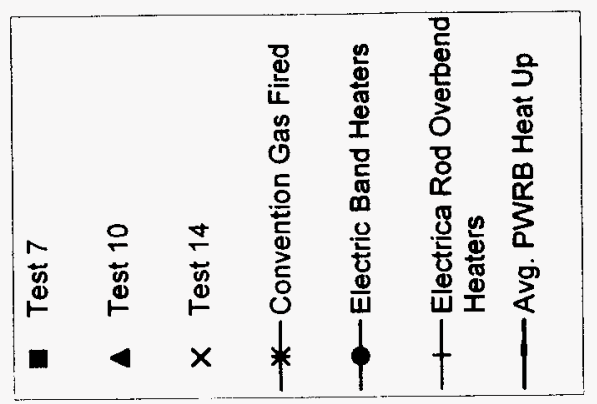

$\sigma$

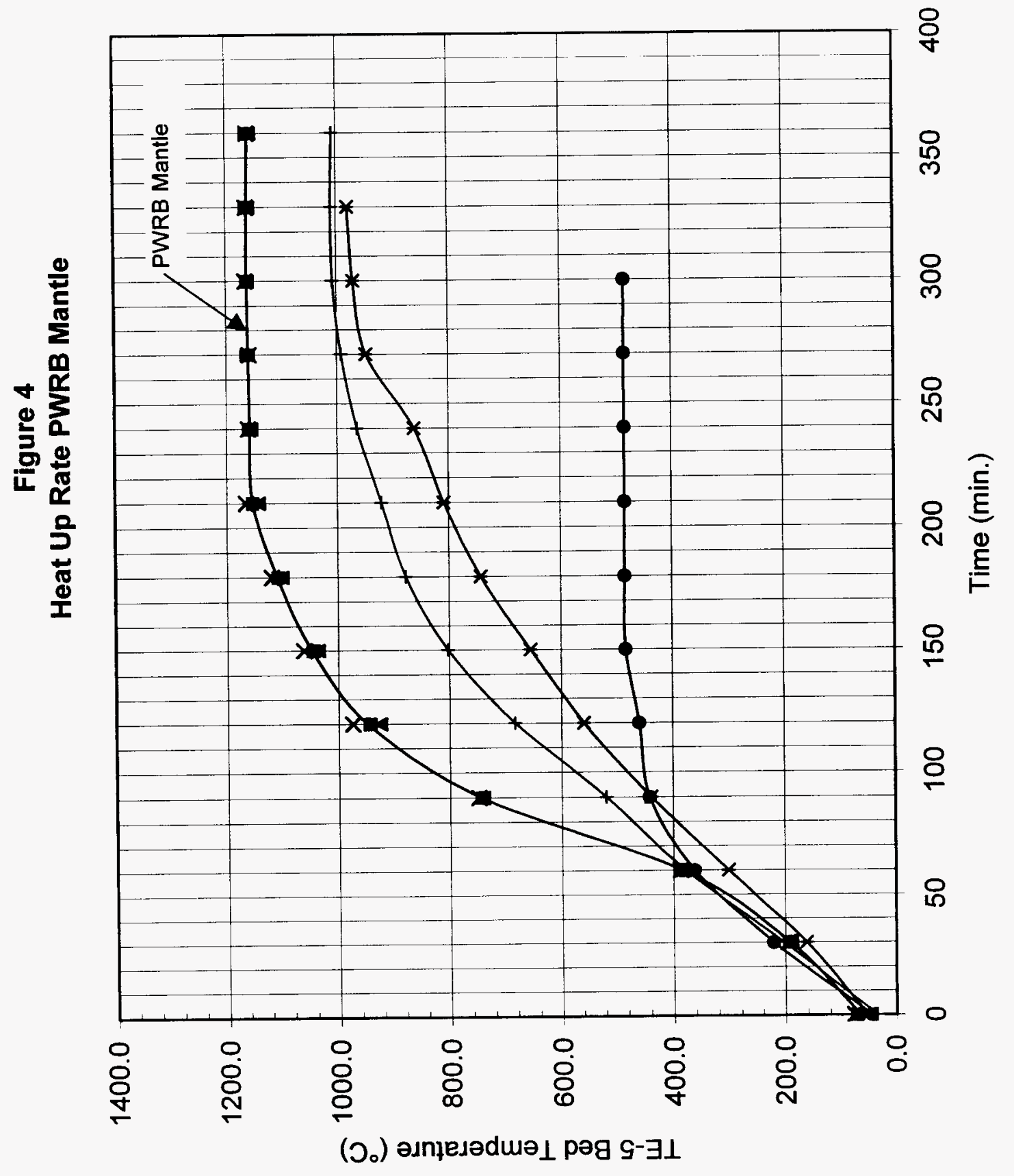




\subsubsection{Maintenance Performance}

The furnace system was operated approximately 750 hours from $12 / 01 / 03$ to $9 / 01 / 04$. The operating temperature of the furnace retort was in the range of $140^{\circ} \mathrm{F}$ to $2120^{\circ} \mathrm{F}\left(60^{\circ} \mathrm{C}\right.$ to $1160^{\circ} \mathrm{C}$ ). There were no signs of degradation of furnace performance.

Following approximately 500 hours of operation, the furnace was dismantled and inspected. Referring to Appendix I ix photograph., some cracks were observed in the top six 2-inch sections of the porous wall. The cracks were small with little separation showing. The decision was made to flow ceramic cement into the cracks.

The furnace was reassembled and restarted. No change in behavior or performance of the furnace was noted before or after the repair. The furnace was put back on line for an additional approximately 250 hours. The furnace performance remained unchanged.

Following the 250 hours of operation the porous wall was reinspected. No additional cracks were noted.

It is speculated that these cracks were formed by too rapid cool down of the furnace after some operations. It will require more operating experience with the furnace to better understand this situation.

\subsubsection{Summary/Results, Conclusions, and Recommendations}

It was concluded that the performance of the test unit engineered and constructed under this program further confirmed that the PWRB heating mantle development offers an opportunity to advance the technology of heating mantles for retort furnace applications and the performance forecasted improvement of higher capacity and efficiency can be realized.

The engineering design developed under this program has performed well and the detailed fabrication approach is anticipated to be readily scaleable to larger size furnaces.

It is recommended that the furnace engineered, designed and operated under the program be operated another 2000 hours in heat treating applications to provide additional information with respect to maintenance performance, and specifically, to evaluate the performance of the porous wall cylinder as designed and fabricated.

\subsection{COMMERCIAL POTENTIAL OF THE DEVELOPMENT}

\subsection{Current Status}

The PWRB heating mantle furnace designed and test operated under this program has performed well from the point of view of operating performance and maintenance requirements for an operating time of approximately 750 hours. 
Commercial applications of the PWRB heating mantle furnaces and reactors have some limited interest at the size level of the test furnace used in this program but the overwhelming numbers of applications involve furnaces considerably larger than the test furnace.

Procedyne has interest to continue with the commercialization of this furnace development. Due to our limited budget for new product development this effort will proceed at a modest rate. The initial effort under way is to find a commercial partner prepared to move on a commercial order and willing to work cooperatively with Procedyne for mutual benefit.

\subsection{Additional Need}

The two major needs to achieve a significant level of commercialization of this development at an increasing rate are:

- Continued and longer term operation of the test furnace to determine longer term maintenance performance. A minimum of 2000 hours is recommended.

- Demonstration of the technology development on a significantly larger scale: a scale-up of at least $26 / 1$ is required for heat-treating applications at a minimum.

Procedyne's plan for satisfying these two major needs are as follows:

i. Long Term Maintenance Performance.

The PWRB mantle heated test furnace designed and constructed under this program has been test operated by Fluidaire Cleaning Systems Incorporated (FCS). This Company performs fluid bed thermal cleaning and heat-treating of metal parts using high temperature retort furnaces. It is planned to continue the operation of up to 2000 additional hours by end of calendar year 2006.

ii. Larger Scale Operation

Procedyne Corp. routinely supplies large size high temperature fluid bed retort reactors and furnaces in important commercial applications. A typical heat-treating furnace of commercial importance has a retort vessel 36 inches diameter and a bed depth of 40 inches. This represents a scale up of $26 / 1$ over the test furnace.

To convince a major Client to accept a PWRB mantle heated fluid bed furnace in place of a conventional mantle heated furnace will require two incentives:

- A guarantee that if the PWRB heating mantle does not perform at least as well as a conventional heating mantle, it will be replaced by a conventional heating mantle at no cost to the Client.

- Provide a financial incentive to the first client and purchase a PWRB heated mantle furnace to reimburse the Client for the costs and inconveniences associated with demonstrating and evaluating this new technology on a full commercial scale. 
Procedyne plans to seek support to fund these guarantees and incentives. The potential cost of these guarantees is estimated at $\$ 400,000$.

\subsection{COMMERCIALIZATION PLAN}

\subsection{Announcement to Industries}

\subsubsection{Technical Papers}

Procedyne presented a technical progress report on this product development at GTI's Natural Gas Technologies Conference and Exhibition, September 30 to October 2, 2002. The title of the paper was "Development of an Innovative Energy Efficient High-Temperature Natural Gas-Fired Retort Furnace by V.C. Shroff and Dr. H.K. Staffin.

A copy of this technical paper is presented in APPENDIX 2.

It is planned to present an updated status report on this development during 2005. This paper will be presented to at least one major technical meeting and exhibition.

\subsubsection{Website Announcement}

Procedyne plans to provide information on the PWRB heating mantle in its website with a proposal for the incentive guarantee to the first heat treating company interested in participating in the commercialization of this development.

\subsubsection{Trade Shows}

Procedyne presented the PWRB heating mantle development at the major ACHEMA 2003 trade show and exhibition in Frankfurt, Germany, June 2003. The technical principle of this development was presented as part of a videotape display. There was significant interest by some visitors to the Procedyne Booth display but none ready to participate in the commercialization without a guarantee.

It is further planned to exhibit at Trade Shows during 2005 and 2006. It is planned to distribute literature at these shows and press releases on the PWRB heating mantle.

ii. Inorganic Chemical Industry

The applications of focus will be catalyst activation reactors, carbon activation reactors, inorganic chemical fluid bed reactors and muffle furnaces. This application requires a scale up of the test furnace developed under this program by a ratio of $1800 / 1$. It is Procedyne's plan to focus commercialization on the 26/1 heat-treating application before considering anything larger. 


\subsubsection{Sales Backup of Sales Leads}

i. Technical Literature

A technical flier will be prepared during 2005 describing the PWRB heating mantle and presenting its benefits over conventional heating mantles, both natural gas fired and electrically heated.

ii. Procedyne sales representatives will be informed of this product development in early 2006, and will be trained in handling sales follow-up of leads.

iii. Standard quotation documents will be prepared for the various standard sizes and price lists.

iv. Sales leads will be contacted by sales representatives and/or a member of Procedyne's sales department.

\subsubsection{Target Industries}

The industries and applications that will be targeted in the first two years of commercialization are as follows:

i. Heat Treating Industry

The applications of focus will be fluid bed heat-treating furnaces, other retort heat treating furnaces, and aluminum melt furnaces.

ii. Inorganic Chemical Industry

The application of focus will be the activation of catalysts for polyolefin plastics manufacture. 


\section{REFERENCES}

1. Silla, H., Shroff, V.C., Porous Plate Radiation Heat Transfer Study, Stevens Institute of Technology, Hoboken, NJ, February 1991.

2. Echigao, R., "Effective Energy conversion Method Between Gas Enthalpy and Thermal Radiation and Application to Industrial Furnaces", $7^{\text {th }}$ International Heat Transfer Conference, Munchen, Vol. 6, pp. $361-366,1982$.

3. Kennedy, L.A., and Ettefagh, "Passing Combustion Gases Through Multilayered Porous Surfaces to Enhance Radiative Heating", ASME/JSME Thermal Engineering Proceedings, Vol., 5, pp. 189-195, 1991.

4. Brown, R.W., "Taking the Black Magic out of High Temperature Nonmetallics", Chem. Eng., April 21, 1958.

5. Silla, H., O'Rourke, D., Development of a High Temperature Natural Gas-Fired Furnace, Stevens Institute of Technology, Hoboken, N.J., July 25, 1998. 


\section{APPENDIX}

1. Photographs of Furnace Installation and Operation.

2. Test Data for Heat-up Rate Testing.

3. Technical Paper describing the PWRB Furnace Development presented at the Gas Technology Institute (GTI) at their "Natural Gas Technologies Conference and Exhibition," September 30 to October 2, 2002.

4. Engineering Drawings

D-17679 Rev. D

D-17664 Rev. C 


\section{APPENDIX I}

1. Photographs of the Furnace Installation and Operation:

i. This first photograph shows the installed furnace in operation in a heat-treating application. The heat treated parts are being unloaded from the furnace.

ii. Furnace Installation showing furnace, control panel, fluidizing air flow meter.

iii. Furnace side view showing discharge of combustion gases from the heating mantle and the stack conveying these gases out of the building into the discharge stack.

iv. Other side view showing the burner system providing high temperature combustion gases to heat the retort vessel. The combustion gas discharge to the stack is also shown.

v. The high temperature retort vessel, which contains the fluidized bed solids, which serves as, the heating medium to the parts being heat-treated.

vi. This photograph shows the porous wall constructed of two-inch high layers cemented together into ceramic cement. The wire shown is monitoring thermocouples to obtain operating information. The retort shown in the prior photograph is centered in this cylindrical porous wall.

vii. This photograph shows the top of a fixture holding parts which are being heat-treated.

viii. This photograph shows a container of parts being removed from the furnace after being heat-treated at high temperature.

ix. This photograph shows the crack developed after first 500 hours of operation. 


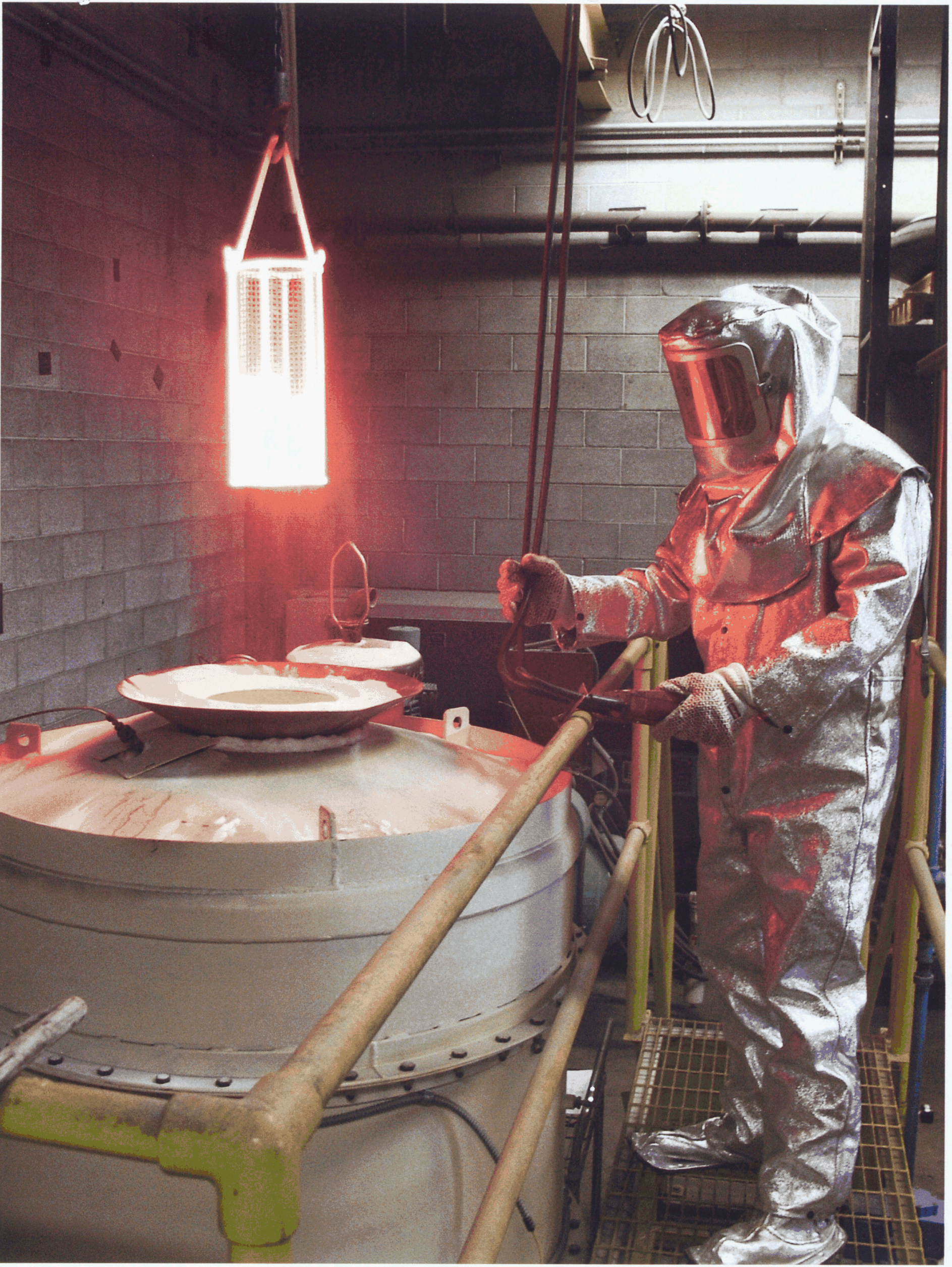




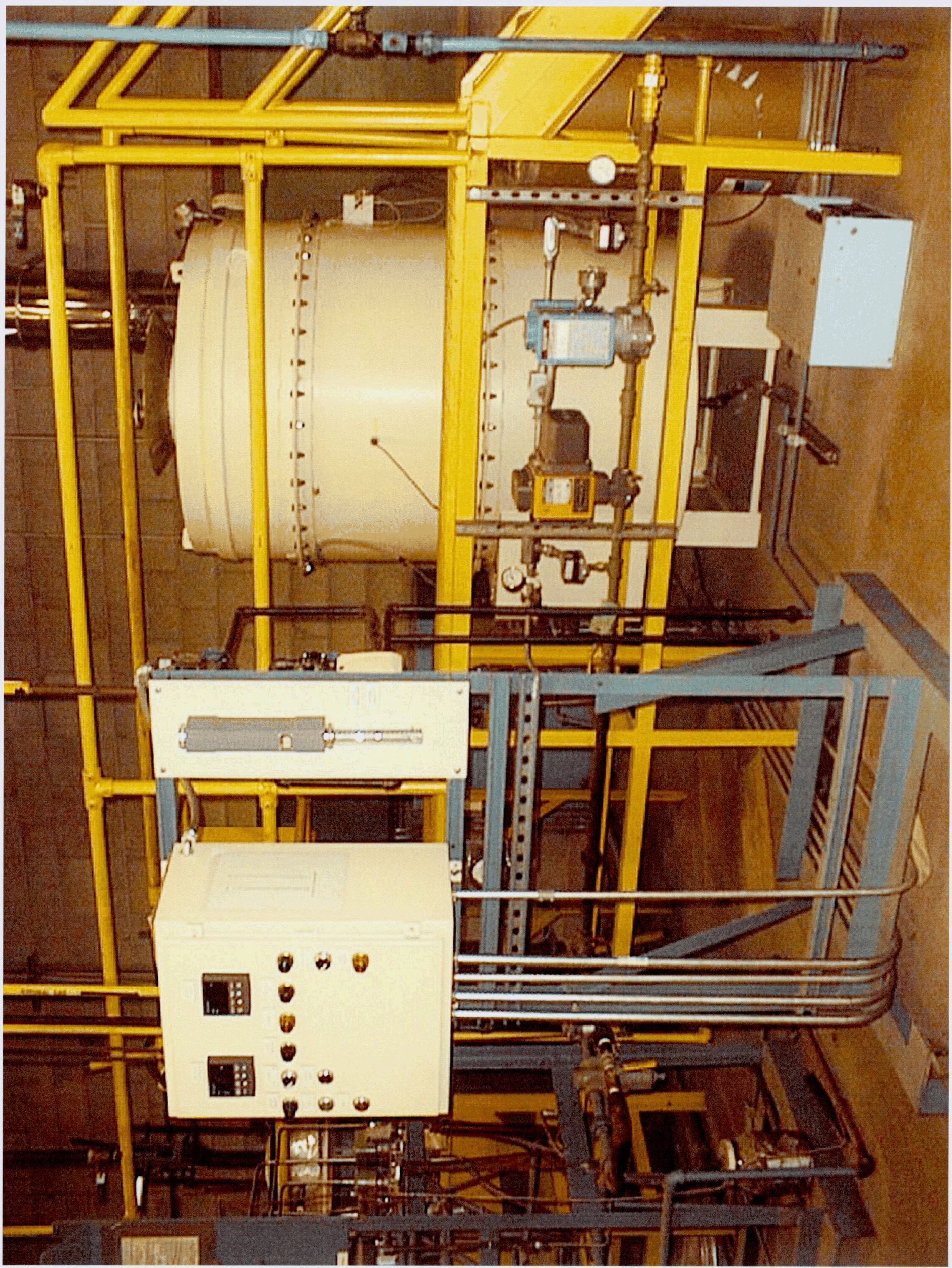


ii

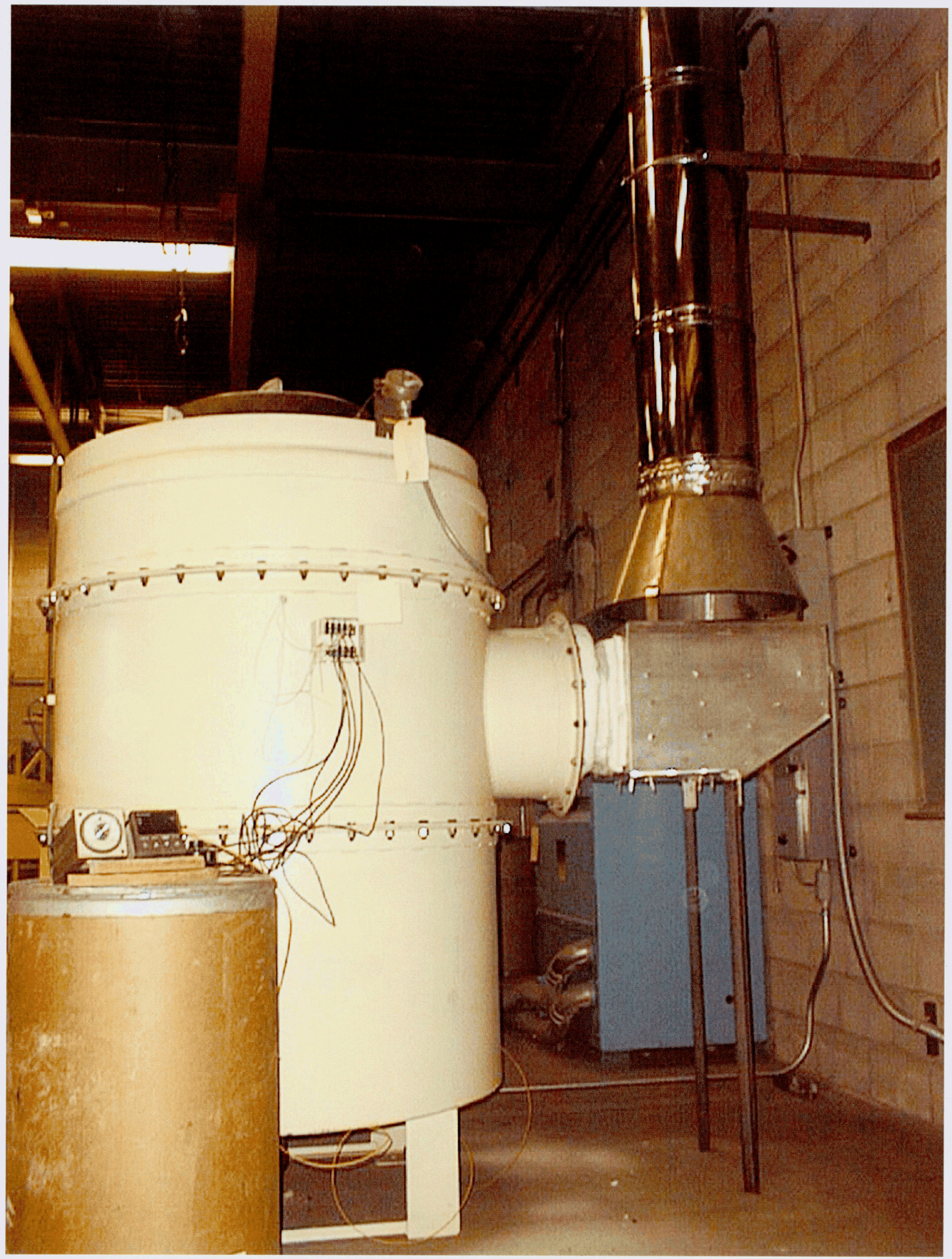




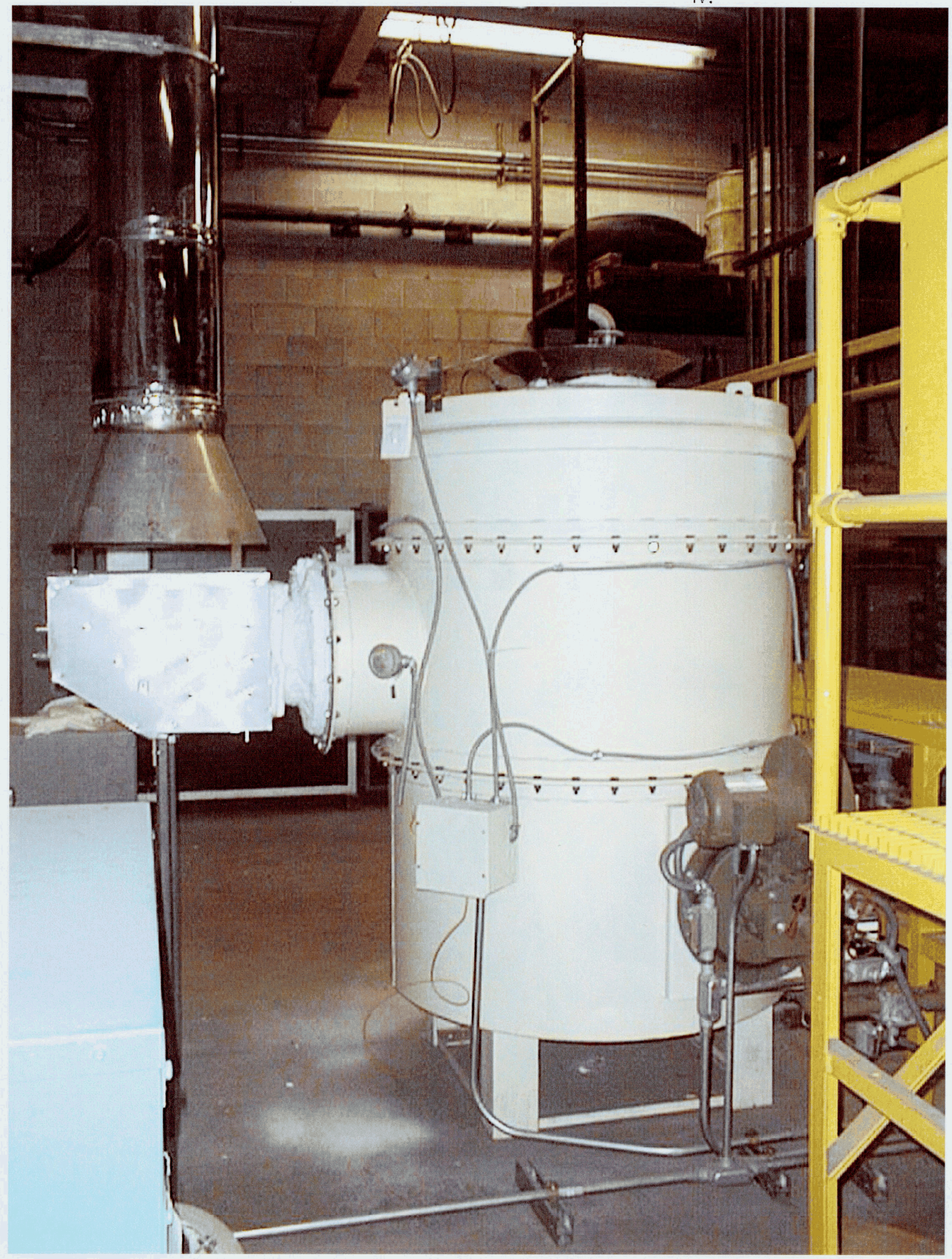


Procedyne Corp.

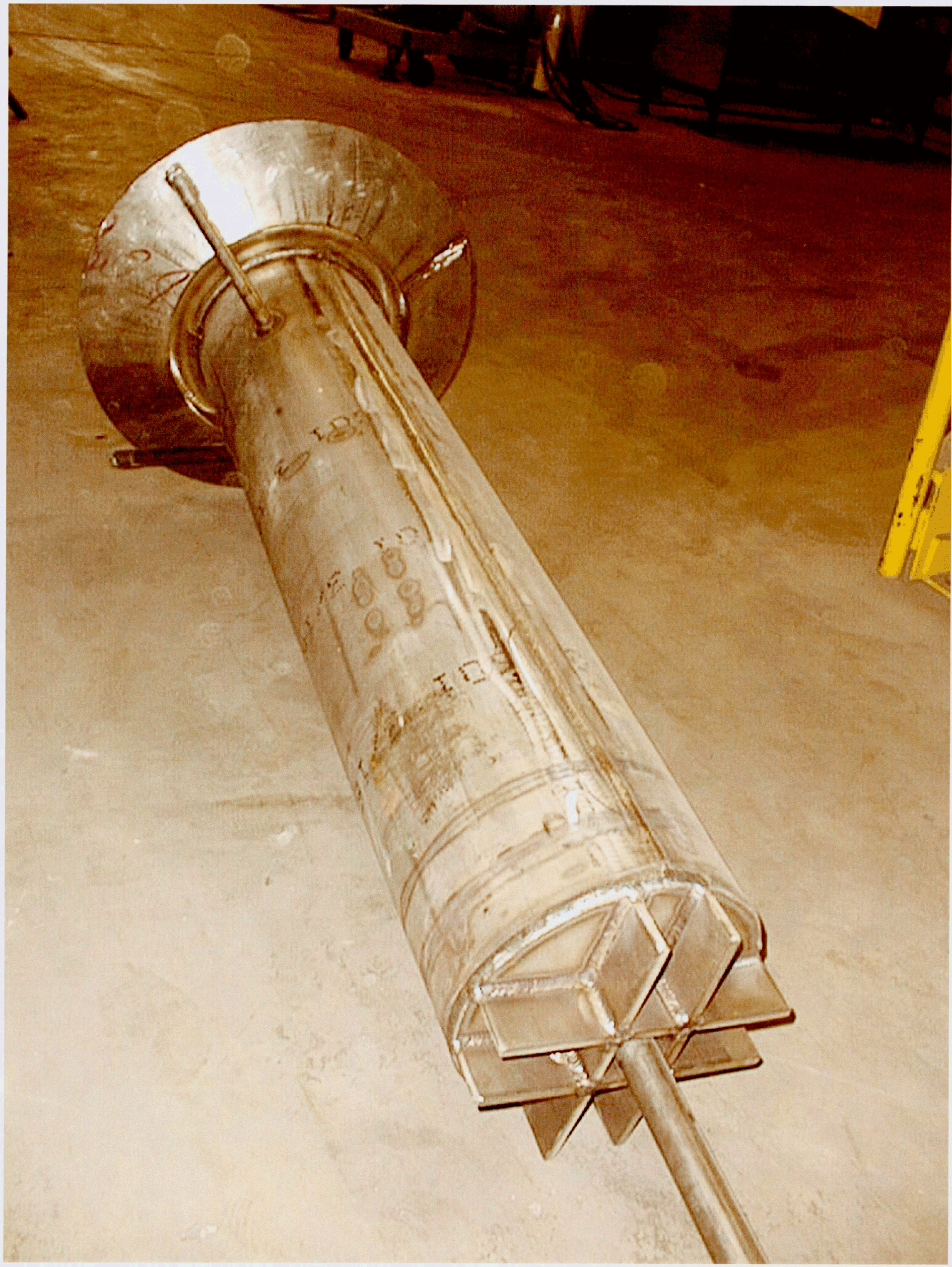



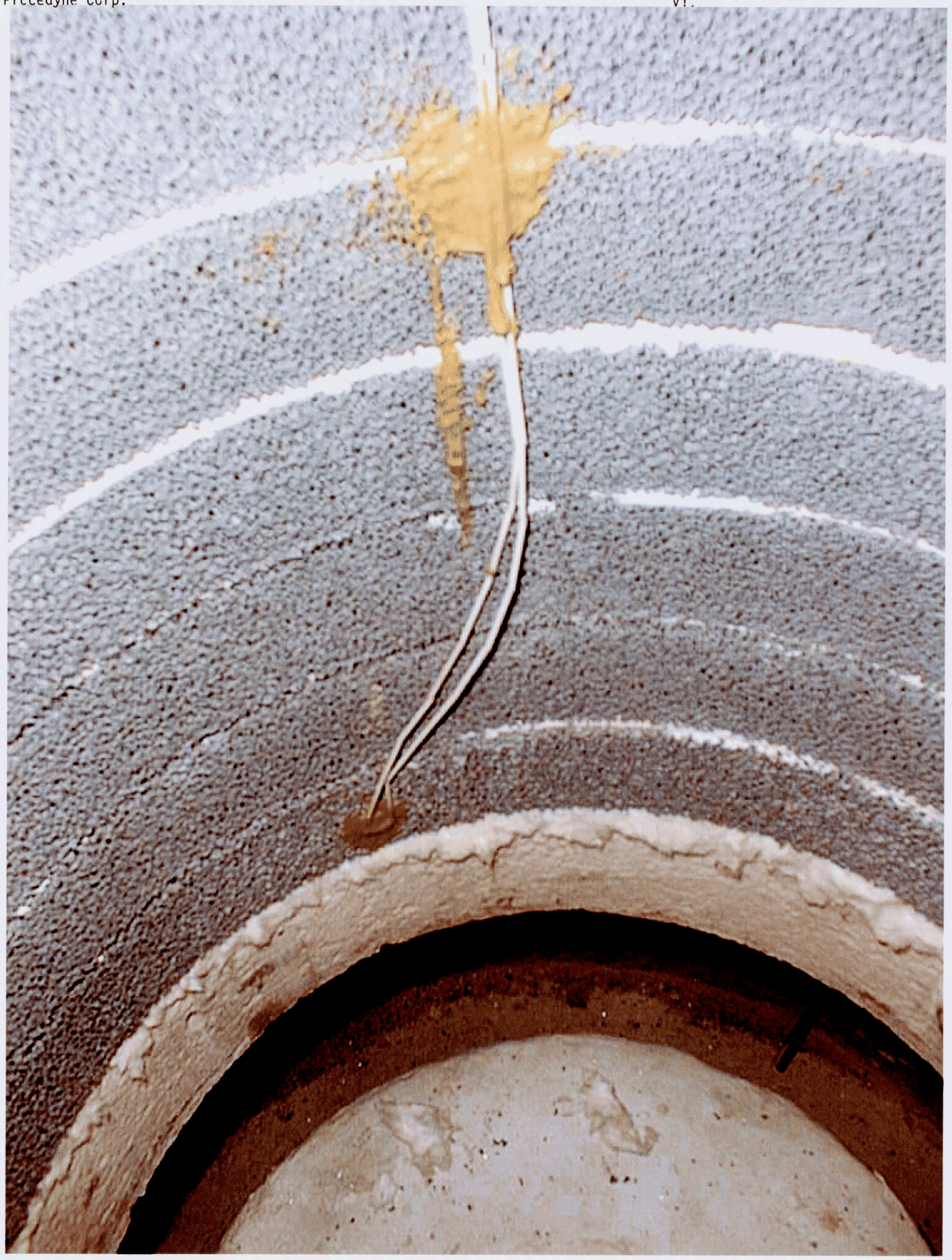


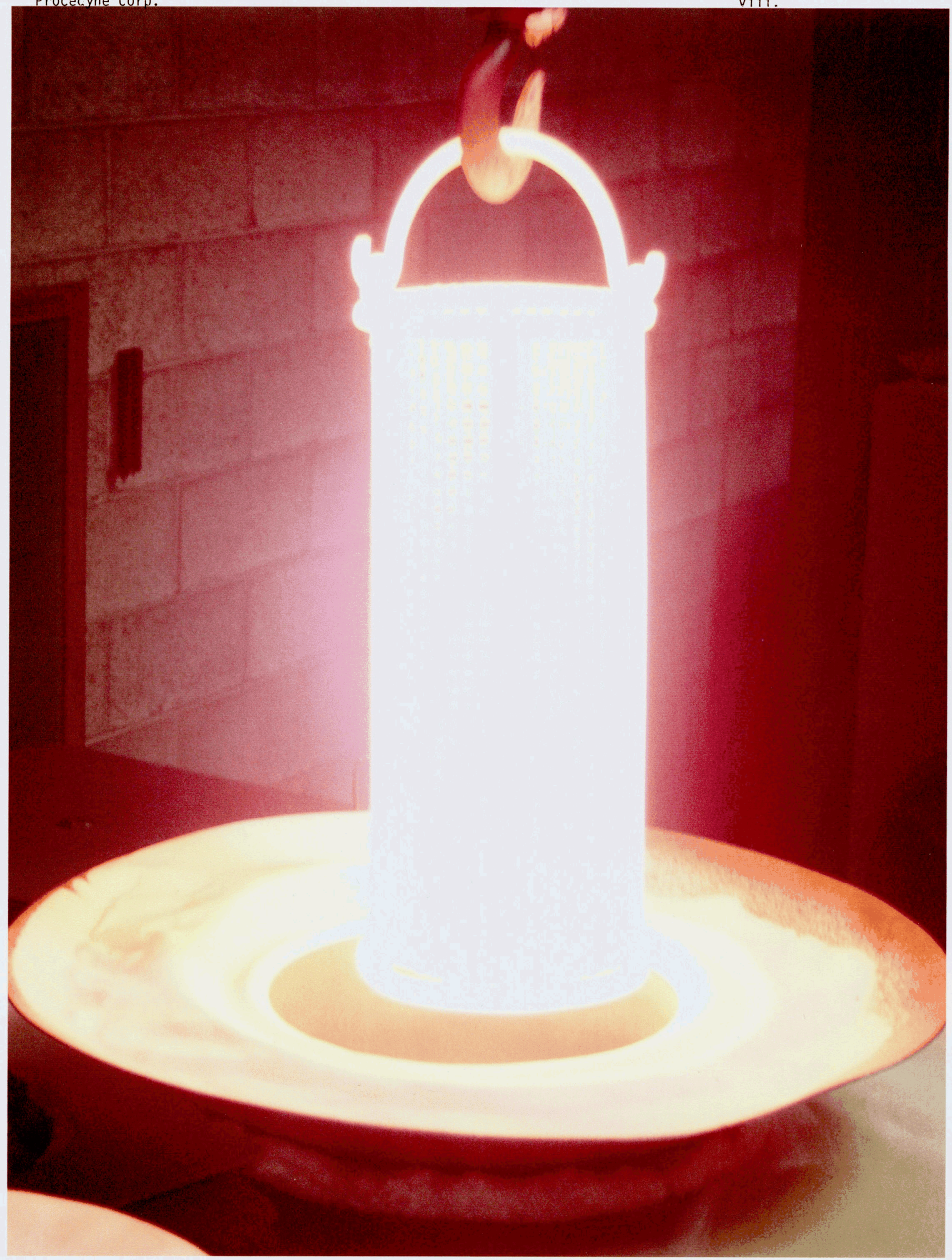




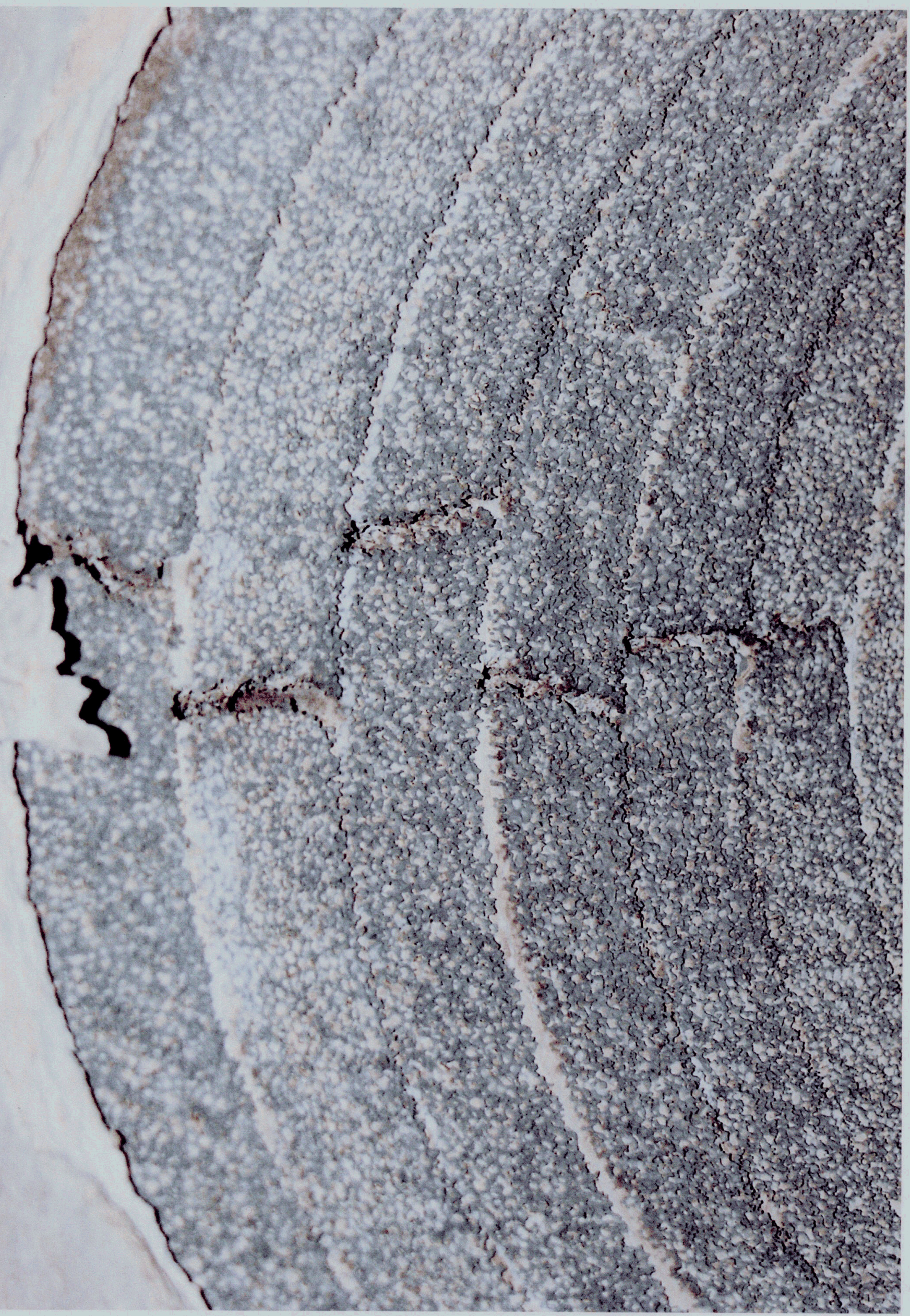




\section{APPENDIX II}

\section{Test Data}

Test No. 7 PWRB Mantle Performance

Page 37

Test No. 10 PWRB Mantle Performance

Page 38

Test No. 14 PWRB Mantle Performance

Page 39

TABLE A-4 Conventional Gas Fired Heat Treating Furnace

Page 40

TABLE A-5 2430 Electrically Heated Furnace and Heaters

Page 41

TABLE A-6 3640 Electrically Heated Furnace Rod Overbend Heaters

Page 42 


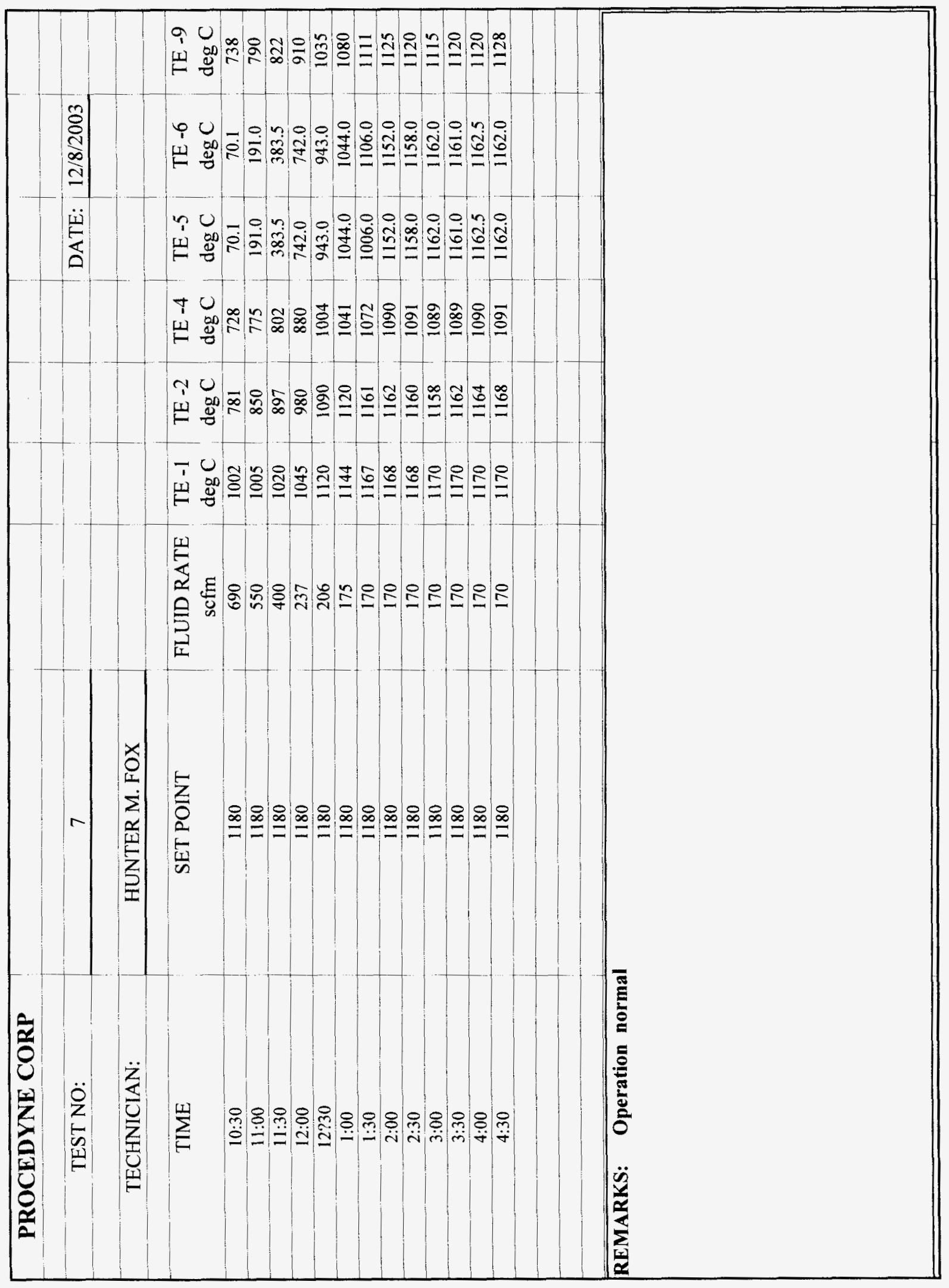




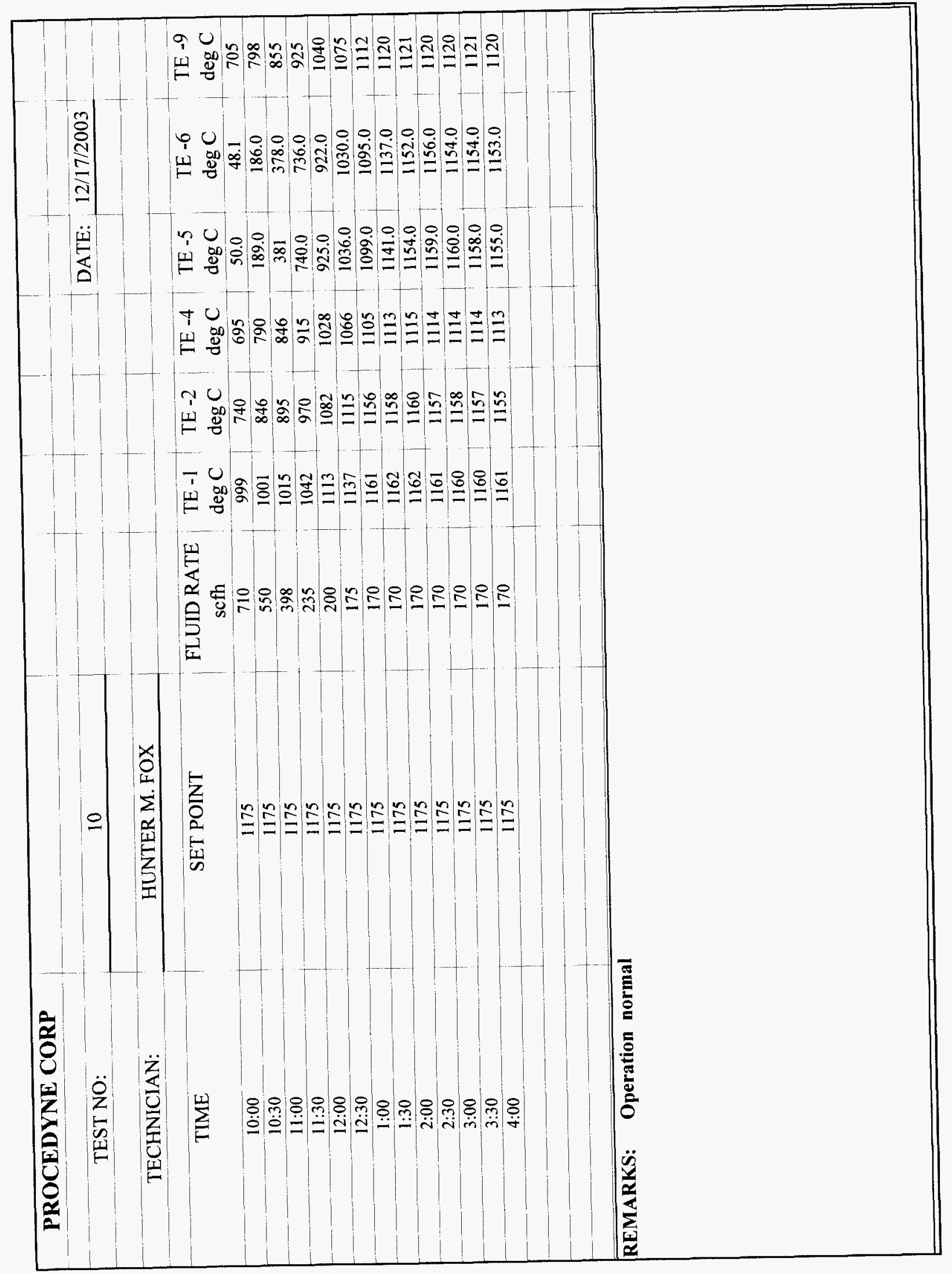




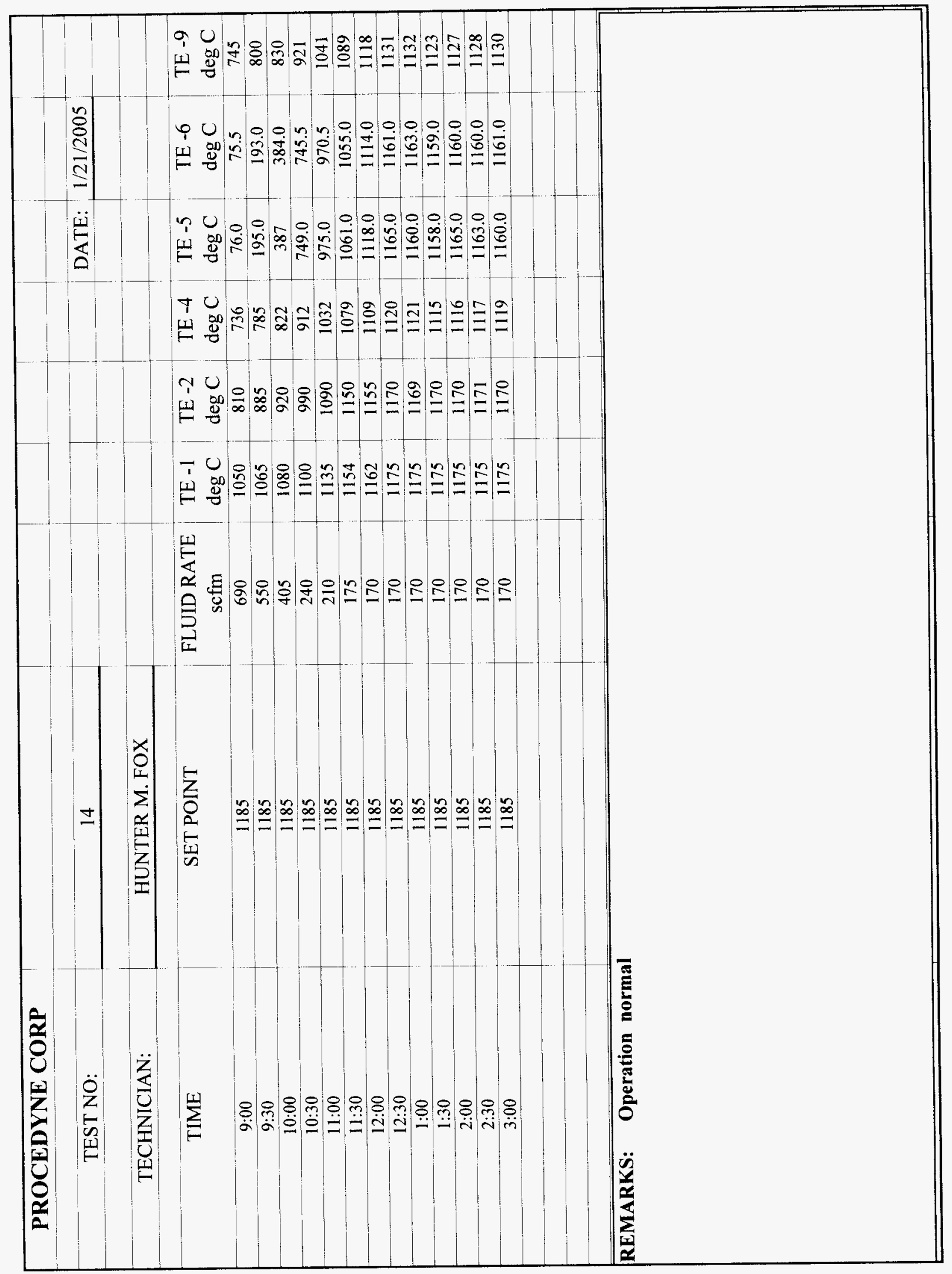


TABLE A-4

CONVENTIONAL GAS FIRED HEAT TREATING FURNACE SCALED TO 1020 FURNACE-

\begin{tabular}{|c|c|c|}
\hline TIME & BED TEMP $^{\circ} \mathbf{C}$ & $\begin{array}{c}\text { FLUIDIZING AIR } \\
\text { SCFIT }\end{array}$ \\
\hline $9: 00$ & 52.0 & $\mathbf{7 1 0}$ \\
\hline $\mathbf{( ; 0}$ & 162.0 & 575 \\
\hline $10: 00$ & 302.0 & 450 \\
\hline $10: 30$ & 438.5 & 360 \\
\hline $11: 00$ & 558.5 & 315 \\
\hline $11: 30$ & 655.0 & 265 \\
\hline $12: 00$ & 743.0 & 236 \\
\hline $12: 30$ & 808.5 & 215 \\
\hline $1: 00$ & 862.0 & 212 \\
\hline $1: 30$ & 948.0 & 195 \\
\hline $2: 00$ & 970.0 & 190 \\
\hline $2: 30$ & 980.0 & 190 \\
\hline
\end{tabular}


TABLE A-5

2430 ELECTRIC FURNACE SCALLED TO 1020 FURNACE BAND HEATERS

\begin{tabular}{|c|c|c|}
\hline TIME & BED TEMP $^{\circ} \mathrm{C}$ & $\begin{array}{c}\text { FLUIDIZING AIR } \\
\text { SCFIT }\end{array}$ \\
\hline $10: 00$ & 44.5 & $\mathbf{7 1 5}$ \\
\hline $10: 30$ & 221.0 & 525 \\
\hline $11: 00$ & 362.0 & 415 \\
\hline $11: 30$ & 441.0 & 358 \\
\hline $12: 00$ & 458.5 & 350 \\
\hline $12: 30$ & 482.0 & 336 \\
\hline $1: 00$ & 483.0 & 336 \\
\hline $1: 30$ & 482.5 & 336 \\
\hline $2: 00$ & 482.8 & 336 \\
\hline $2: 30$ & 483.2 & 336 \\
\hline $3: 00$ & 482.7 & 336 \\
\hline
\end{tabular}


TABLE A-6

3640 ELECTRIC FURNACE SCALED TO 1020 FURNACE ROD OVERBEND HEATERS

\begin{tabular}{|c|c|c|}
\hline TIME & BED TEMP $^{\circ} \mathrm{C}$ & $\begin{array}{c}\text { FLUIDIZING AIR } \\
\text { SCFIT }\end{array}$ \\
\hline $9: 00$ & 35.0 & 730 \\
\hline $9: 30$ & 203.0 & 550 \\
\hline $10: 00$ & 378.5 & 415 \\
\hline $10: 30$ & 518.0 & 325 \\
\hline $11: 00$ & 682.5 & 255 \\
\hline $11: 30$ & 802.0 & 225 \\
\hline $12: 00$ & 878.0 & 205 \\
\hline $12: 30$ & 921.0 & 195 \\
\hline $1: 00$ & 964.5 & 196 \\
\hline $1: 30$ & 992.0 & 185 \\
\hline $2: 00$ & 1007.0 & 185 \\
\hline $2: 30$ & 1009.5 & 185 \\
\hline $3: 00$ & 1007.0 & 185 \\
\hline
\end{tabular}




\section{APPENDIX III}

\section{Technical Paper:}

Development of an Innovative Energy Efficient High Temperature Natural Gas-Fired Retort Furnace 


\title{
DEVELOPMENT OF AN INNOVATIVE ENERGY EFFICIENT HIGH TEMPERATURE NAURAL GAS-FIRED RETORT FURNACE
}

\author{
Vijay C. Shroff, M.S., M.E. \\ Manager, Process Technology \\ H. Kenneth Staffin, Ph.D. \\ Chairman \& CEO \\ Procedyne Corp. \\ New Brunswick, New Jersey 08901, U.S.A. \\ www.procedyne.com
}

\section{ABSTRACT}

Worldwide manufacturers and processors have a strong interest in higher capacity more energy efficient natural gas-fired retort furnaces, which find many important applications in major industries.

Procedyne Corp., with partial funding from industrial and governmental agencies, has developed a new high capacity energy efficient heating mantle termed "Porous Wall Radiation" (PWR) Mantle in which the combustion gas flows through a porous wall surrounding the retort in a radial flow direction away from the retort wall transferring heat by conduction and convection to the porous wall, which then radiates heat to the retort.

Theoretical studies verified by bench-scale testing demonstrated that operating in the temperature range of 1600 to $2350^{\circ} \mathrm{F}$, this design transfers heat to the retort at rates 1.8 to 2.4 times that in conventional heating mantles.

Procedyne has recently engineered and constructed an industrial size furnace with the PWR Mantle.

In this paper, the furnace design and the supporting experimental results are presented. 


\section{INTRODUCTION}

The gas-fired heating mantle for indirectly heating a retort vessel is an important processing element in heat treating furnaces, chemical reactors, fluid bed reactors and related equipment for applications in the heat treating, metal processing and inorganic chemical industries. There are an increasing number of commercial processes involving the use of high temperature retort furnaces, particularly in the temperature range of $1000^{\circ} \mathrm{F}$ to $2350^{\circ} \mathrm{F}$.

The current state-of-the-art technology in gas-fired heating mantles contains a number of important deficiencies which limit the number of successful commercial applications. It has been concluded that if current technology in gas-fired mantles were advanced, particularly in the higher temperature range, the number of gas-fired heating mantles in commercial applications would increase significantly.

The effectiveness of natural gas utilization for heating a high temperature reactor or retort can be improved if the radiative component of the heat transfer coefficient to the reactor is increased. At high temperatures, heat is transferred to the retort by convection from the combustion gases and by radiation from the surrounding walls. When high temperature combustion gases flow through a porous-ceramic wall, convective heat transfer from the gases to the wall increases the wall temperature. The porous-ceramic wall then radiates the heat to the retort. At high temperatures, the radiative heat transfer to the retort becomes more significant than the convective heat transfer.

The Gas Technology Institute (GTI), formerly known as Gas Research Institute (GRI) of Chicago, Illinois, sponsored a significant development program at Procedyne Corp., New Brunswick, New Jersey to increase the heat transfer coefficient from a natural gas heating mantle to the retort vessel using various geometric configurations in the heating mantle annulus including the radiant porous wall concept. The development program evaluated a number of approaches to achieve the objective of increasing the heating capacity of gas fired heating mantles.

\section{TECHNICAL PRINCIPLE}

The Radiant Porous Wall concept is based on the conduction/radiation behavior of a porous barrier when passing the high temperature combustion gases through the material. It has been experimentally demonstrated and reported in the literature that the presence of a gas-permeable (porous) layer of material can be used to augment the heat transfer to a solid metal object in some gas-fired heat transfer situations. Based on technical considerations and evaluations performed during the initial conceptual effort, and subsequently confirmed by a heat transfer experimental program, this behavior appears to be applicable to the heat transfer situation typically encountered in a gas-fired heating mantle application. The reported extent of heat transfer rate enhancement is sufficiently high to justify a detailed evaluation of this concept.

When gases at high temperature are passed through the surface or face of a porous cellular structure, the temperature of the face is increased by convective heat transfer from the gases to the cellular walls forming the porous structure. 
As this cellular area of porosity increases, the temperature of the porous structure forming the face (including the infinitesimal depth of the porous structure behind the face) increases, approaching the temperature of the gases entering the face. Conceptually, if the cellular surface area of the porous structure becomes infinitely large, the face of the porous structure equals the temperature of the gases entering the face.

On the other hand, as the surface area of porosity of the cellular structure decreases, the heat transfer rate from the high temperature gases per unit depth decreases as the gases pass through the face of the porous structure and the resulting face temperature becomes lower than gas temperature. This heat transfer situation is shown diagramatically in Figure 1.

This principle can be expressed in mathematical terms as:

$$
\begin{aligned}
& \operatorname{Lim}_{\mathrm{f}_{\mathbf{f}}}=\mathrm{Tg}_{\mathrm{i}} \\
& \text { Acw } \rightarrow \propto
\end{aligned}
$$

where

$T_{\mathbf{f}} \quad=$ face temperature of porous structure

Acw = area of cellular wall per unit volume of porous structure

$\mathrm{Tg}_{\mathbf{i}}=$ temperature of gases entering the face of the porous structure

Clearly, for the application involving gas fired heating mantle, the theoretical case with infinite area of cellular wall per unit volume of porous structure yields the maximum radiation face temperature resulting in a maximum heat transfer rate from the porous wall, through the mantle annulus to the retort wall.

In addition, an energy balance on the mantle shows that this gives the lowest exit temperature, $\mathrm{Tg}_{0}$, of the combustion gases leaving the mantle. Thus highest efficiency of heat transfer from the combustion gases to the retort is achieved.

During the Phase I of the program funded by GTI, computer simulations were made of the radiation porous wall mantle, one using the "infinite area" definition of the cellular wall, and one assuming the cellular wall is of finite area formed by parallel tubes or orifices, termed "orifice area". As expected, the infinite area model predicated more favorable heat transfer rates and higher energy efficiencies than the orifice area model, but both predicted excellent performance compared to conventional gas fired heating mantle.

\section{CONFIGURATION AS A GAS FIRED HEATING MANTLE}

The radiant porous wall concept is shown as a gas fired mantle heating a retort furnace in Figure 2. A cylinder of high porosity material with wall thickness of $1 / 2$ inch to 3 -inch thick is located in the annulus space of the heating mantle of a gas-heated furnace. This porous wall barrier cylinder becomes the radiant surface of the heating mantle. The installation of this cylinder results in the system now forming two annuli in the mantle. In this configuration, the basic structure of the system consists of three cylindrical structures. 


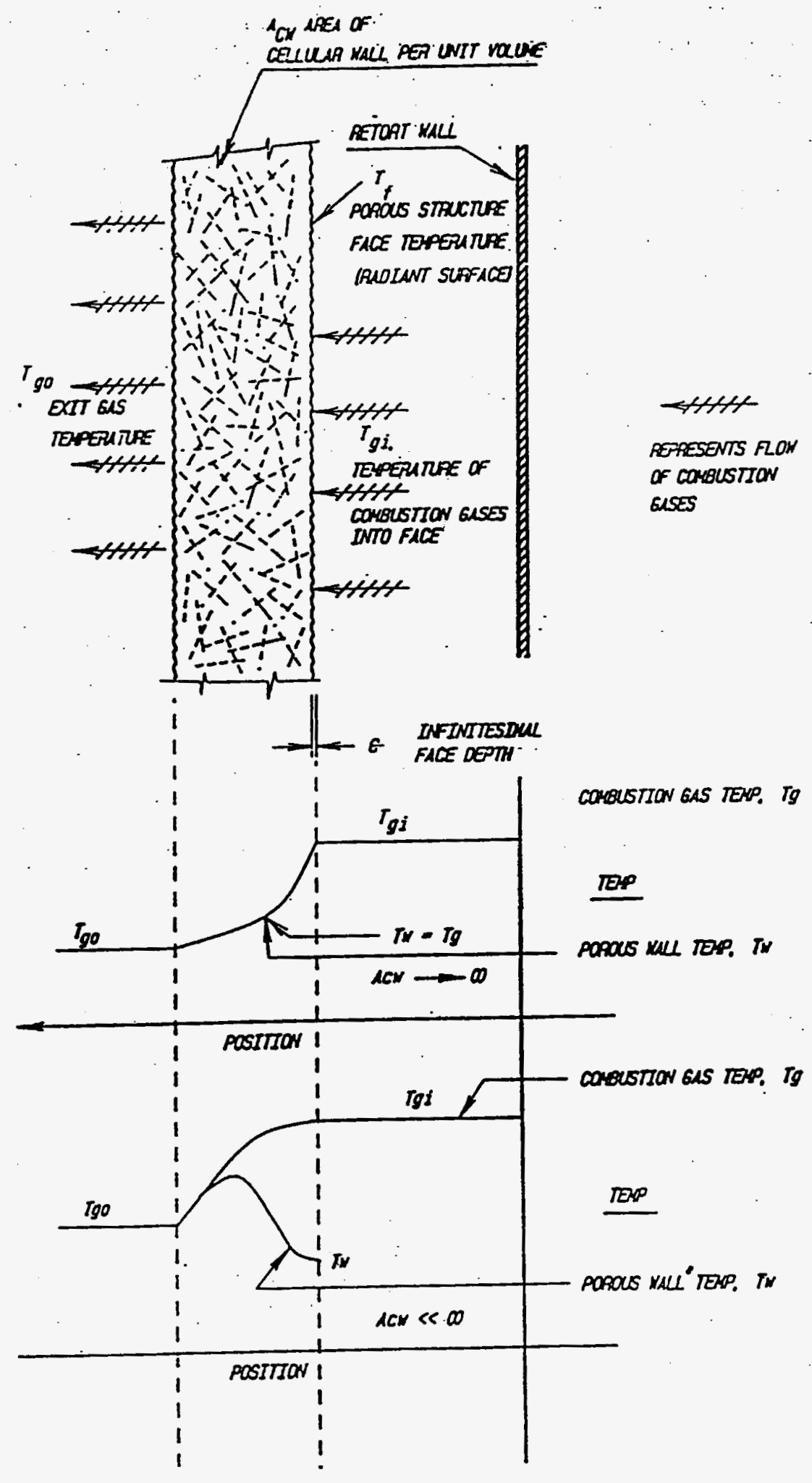

Figure 1: Porous Wall Radiation Barrier (PWRB) Concept 


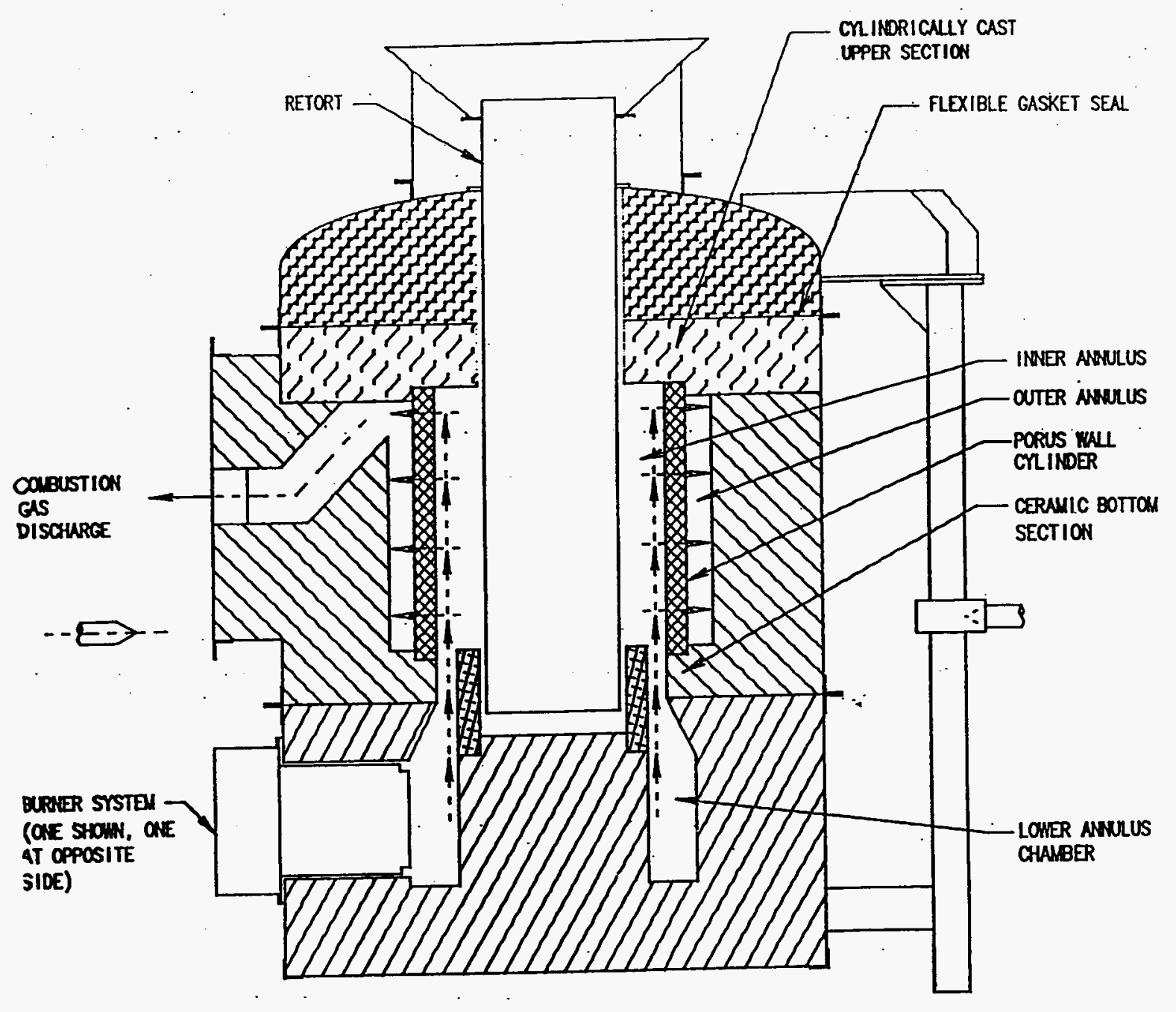

LINE LEGEND

$\rightarrow \rightarrow$ DENOTES DIRECTION OF FLOW OF HOT GAS

Figure 2: Conceptual Design of Commercial Scale PWRB Heating Mantle 
The inner most cylinder is the metal retort, the center one is the porous wall cylinder, and the outer most is the refractory insulation of the surrounding steel shell. The inner annulus is then the space between the retort's outer surface and that of the porous cylinder's inner surface. The outer annulus is the space between the porous cylinder's outer surface and that of the refractory insulation's inner surface.

One or more burners are mounted near the bottom of the gas-heated mantle and fired into the annulus chamber which serves as a manifold to distribute the combustion gases radially around the mantle.

The combustion gases are then directed up through the inner annulus, across the inner porous cylinder surface, through the porous wall and out of the outer porous cylinder surface. The flue gases then leave the unit through the outer annulus space to a flue gas exhaust port.

Since the objective of this design is to provide for vertical distribution and uniform flow of the combustion gases through the porous wall cylinder to the gas discharge port with little or no by-passing, the following design features were incorporated to achieve this objective:

1. The porous wall cylinder, was fabricated using sections. The sections were joined with a "keyed" construction and a suitable ceramic binder.

2. The porous wall section is under compression at the top and bottom edges by the upper section of cast insulation and is supported up by the porous wall cylinder as shown in Figure 2. In addition, the cast upper section is sealed to the shell with a flexible gasket seal.

3. The pressure drop through the porous wall is limited to that required to distribute the gas phase uniformly throughout the radiation annulus (inner annulus) but no greater. This feature minimizes the pressure drop across the seals.

It was estimated that a pressure drop of less than 1 inch W.C. is sufficient to insure flow uniformity at each elevation of the porous wall.

Computer simulations of the heat transfer performance of furnace shown in Figure 2 predicted that the radiant porous wall mantle would achieve heat transfer rates of 6 to 8 times that achieved in conventional gas-fired heating mantles. The two previously described heat transfer models used for the computer simulations, gave different estimates for heat transfer rates, but both models predicted major improvements over conventional gas-fired mantles.

It was the objective of the radiation porous wall heat transfer experimental program to determine whether the heat transfer rates that were predicted by computer simulations were actually achievable. It was an additional objective of the heat transfer study to determine which computer model better simulated the radiant porous wall mantle and whether it was influenced by the characteristics of the porous wall material of construction. 


\section{EXPERIMENTAL FACILITY}

The test system for both the porous plate and the porous cylinder furnaces, consists of four subsystems: the burner system, the combustion-gas system, the heat-transfer chamber and the data acquisition system. The heat-transfer chamber, used to measure heat transfer coefficients, consists of either a porous plate or a porous cylinder and an air cooler to simulate a reactor or retort.

The flow diagram for the test system using the porous plate heat transfer chamber is given in Figure 3. The test system using the porous cylinder heat transfer chamber is the same except for the heat-transfer chamber, and is shown in Figure 4. Natural gas and air are metered, mixed, and burned in the furnace. The furnace was designed by the Procedyne Corp. to operate at the design temperature of $2500^{\circ} \mathrm{F}$. The hot combustion gases flow through the heat transfer chamber. Heat is transferred to the air cooler by convection from the combustion gases and by radiation from the porous plate or cylinder (porous wall). After flowing through the porous wall, the combustion gases flow up the chimney and into a canopy hood located above the furnace. The combustion gases, along with ambient air, are drawn into the hood by the fan located downstream of the spray cooler. Then, as shown in Figure 3 and 4, the mixed gases are cooled in the spray cooler and blown into a laboratory hood by the exhaust fan.

\section{Heat Transfer Chamber}

Porous Plate. The porous plate heat transfer chamber consists of the porous ceramic plate and the air cooler shown in Figure 5. After combustion, the hot gases flow through a tapered channel to the chamber. The chamber consists of a channel $(12.0 \times 2.0$ inches $)$ with the porous plate placed on top and the air cooler on the bottom. The bottom edge of each porous plate (13.5 $x 13.5$ inches) is placed on 1/8 inch strips of fibrefrax-ceramic paper to prevent leakage of combustion gases. To prevent lifting of the plate and to form a better seal, firebricks are placed along the upper edge of the porous plate, reducing flow area (12.0 x 12.0 inches).

The air cooler consists of a channel ( $0.25 \times 12.0$ inches) construction of $1 / 8$ inch-thick Inconel 600 plates welded together. The narrow channel distributes the air flow uniformly across the chamber. Air from an 80 to 100 psig line is throttled to 13.5 psig before flowing it to the cooler. The air flow was co-current to the flow of combustion gases. Heat is absorbed by air. After leaving the cooling chamber, the hot air mixes with the combustion gases before entering the spray cooler.

Porous Cylinder. The flow system for the cylindrical heat transfer chamber is shown in Figure 6. The heat transfer chamber consists of the porous ceramic cylinder and the Inconel-air cooler. After combustion, the hot gases flow through a tapered channel to the chamber. In the chamber, the combustion gases heat the air as it flows up, concurrent to the flow of the combustion gases, before exiting the chamber. The air cooler is a bayonet-type cooler. Air at 13.5 psig supply pressure flows down a central $3 / 4$ inch SS 316 pipe to the bottom of the cooler and then upward through an annular channel. Insulation covering the central pipe minimizes preheating of the downward-flowing entering air by the upward-flowing hot air. 


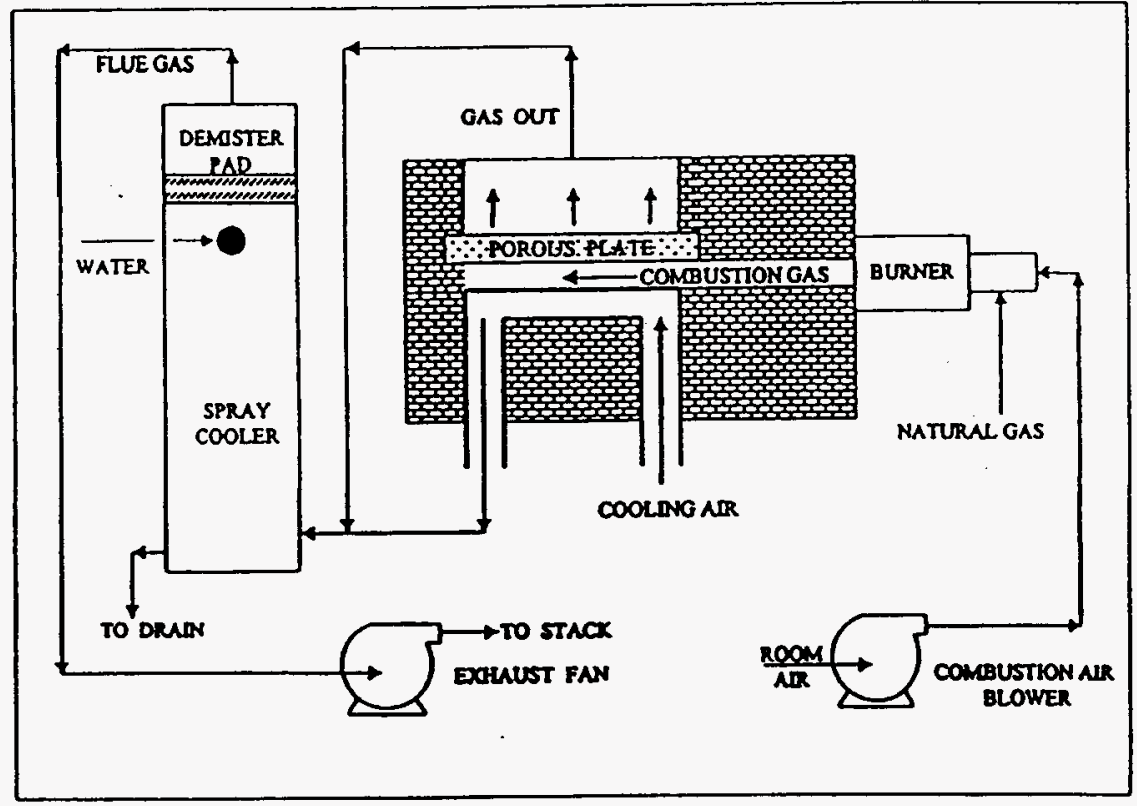

Figure 3. Porous Plate Flow Diagram

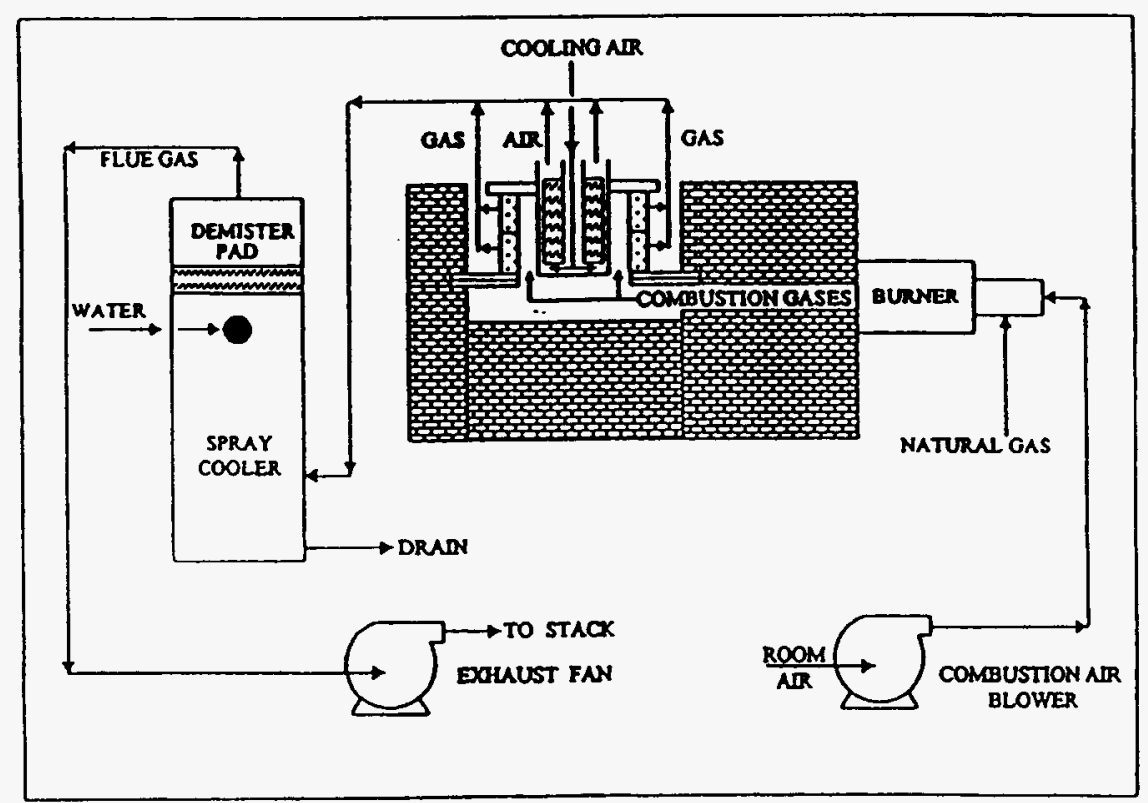

Figure 4. Porous Cylinder Flow Diagram 


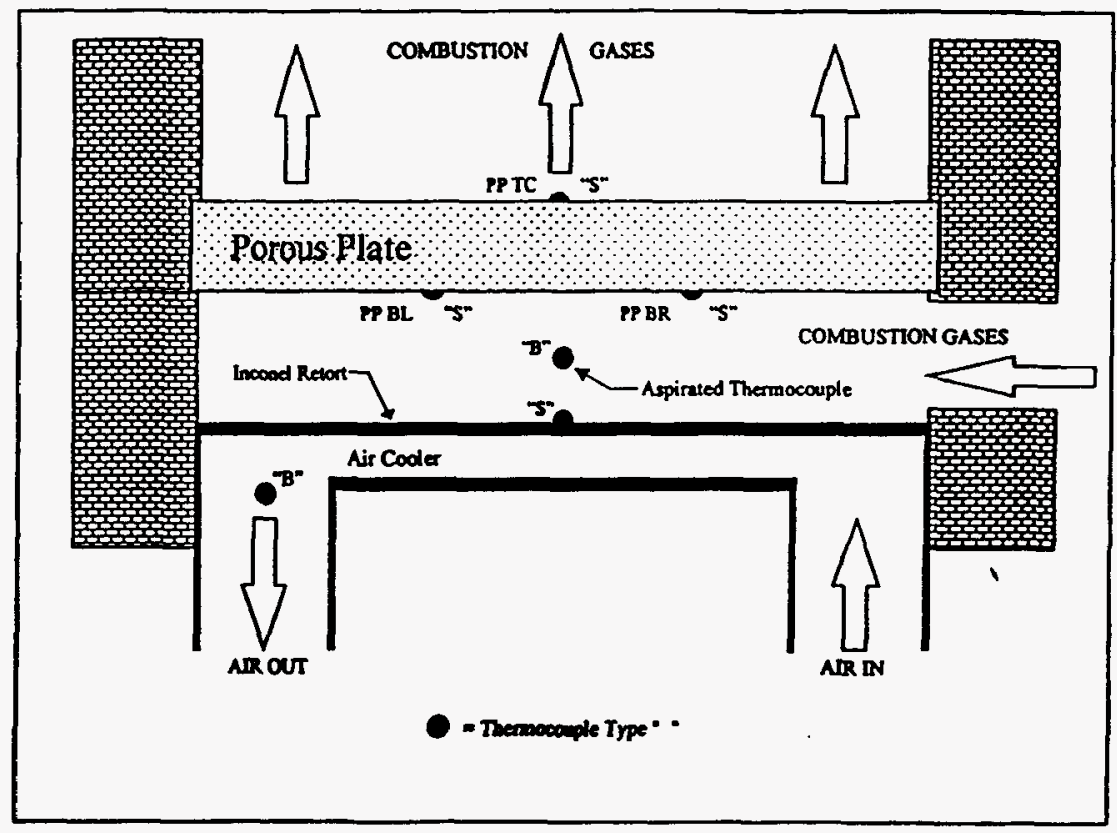

Figure 5. Porous Plate Heat Transfer Chamber

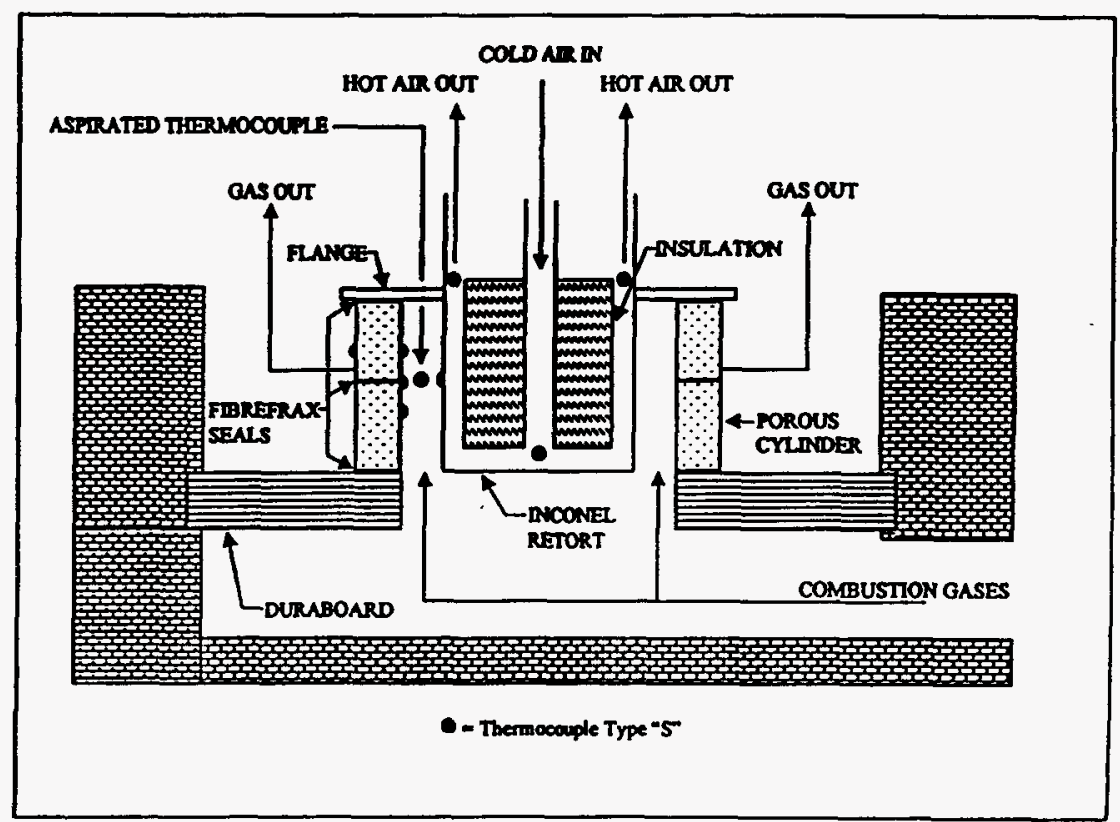

Figure 6. Porous Cylinder Heat Transfer Chamber 
The porous cylinder is composed of two-ceramic rings separated by fibrefrax-ceramic paper to prevent the combustion gas from leaking. The fibrefrax paper in contact with the cylinder is cemented to the porous surface using the LDS cement. A ring of fibrefrax paper is also cemented to the top surface of the Duraboard@ insulation using the LDS cement. Thus, a seal is formed when the porous ring is placed on the Duraboard(C) insulation. The joint between the two porous ceramic rings contains three rings of fibrefrax paper. Two of the three-fibrefrax rings are cemented to the ends of the porous rings. The third ring is placed in between the two-fibrefrax rings. During installation the seal is compressed from $3 / 8$ to $1 / 8$ inch. This fibrefrax paper permits a better seal and mechanical separation if one of the porous rings is damaged after installation.

A ring of fibrefrax paper is also cemented to the bottom-flange surface of the air cooler using an inorganic zircon-base cement (Sauereisen No. 8, Electrotemp Cement, Sauereisen Co., Pittsburgh, PA). Thus, a seal is formed when the air cooler is placed on the cylinder. To prevent lifting of the cylinder and the air cooler, as well as to ensure a seal between all of the layers of fibrefrax paper, the porous cylinder and air cooler were designed to be anchored down with two threaded rods supported externally. However, the threaded rods failed because of the differential thermal expansion. Also, it was found that the threaded rods were unnecessary because the weight of the air cooler was sufficient to anchor the porous cylinder and to ensure a seal.

\section{Experimental Procedures}

Porous Plate. Four different porous plates were tested to determine the effects of plate material and thickness on heat transfer. The firebrick plate was nonporous and was used as a reference. Firebrick is the material traditionally used in industrial furnaces.

Figure 5 shows the relative locations of the thermocouples, and Figure 7 gives the exact location of the thermocouples. It was expected that the lateral temperature gradient on the plate surface would be relatively flat. To check the symmetry of the temperature profile across the plate and to allow for some redundancy, two-thermocouple junctions were placed 2.5 inches apart at the bottom of the pate, as shown in Figure 7. Another thermocouple was placed on top of the plate to determine the temperature drop across the plate in the direction of gas flow.

Porous Cylinder. The results of the porous plate tests showed that silicon carbide (SiC) has one of the best heat transfer coefficients and a high mechanical strength. Based on these results and the fact that it is a common material, a hollow-porous $\mathrm{SiC}$ cylinder was tested. The porous cylinder consisted of two rings sealed together as described previously. The heat transfer properties of the silicon carbide, as well as the mechanical strength of the joint, were evaluated. Four temperature measurements were made on the cylinder, as shown in Figure 6. Figure 8 gives the exact location of the thermocouples. On the inside of the cylinder, two thermocouples were placed 0.5 inches from the joint, one above and one below the joint. A third thermocouple was placed directly on the joint. On the outside of the cylinder the fourth thermocouple was placed 0.5 inches above the joint. 


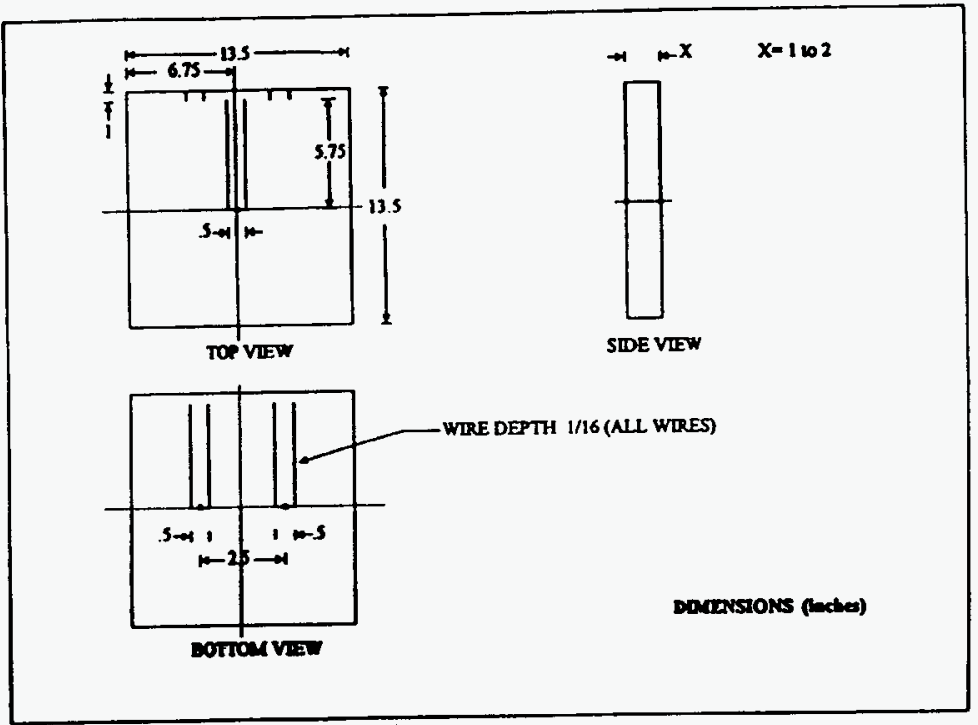

Figure 7. Porous Plate Thermocouple Locations

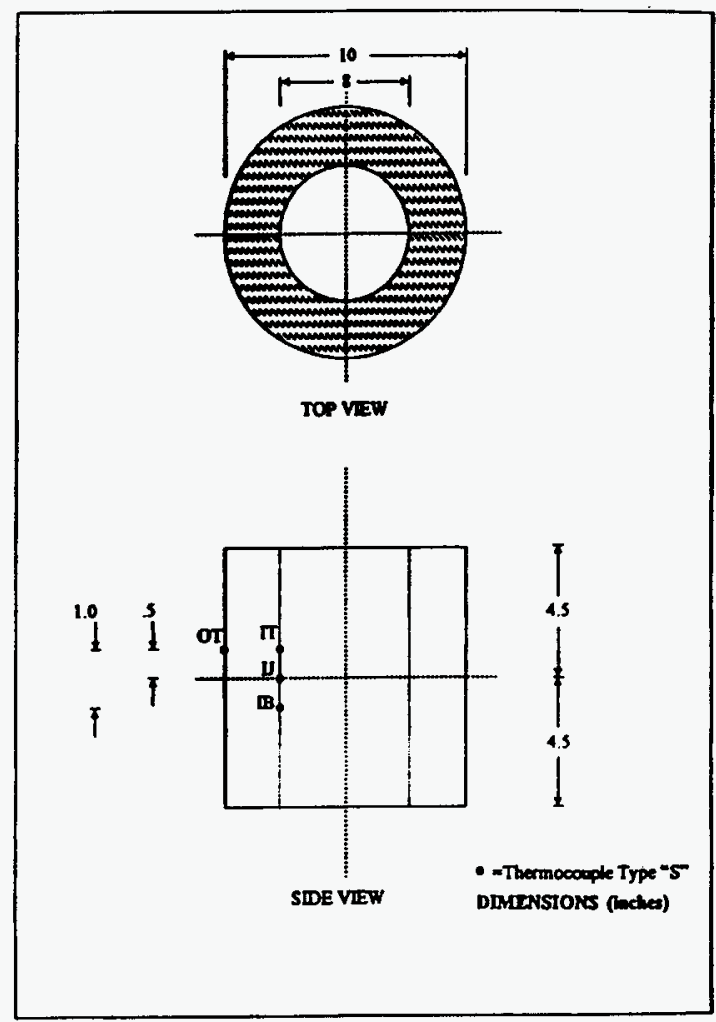

Figure 8. Porous Cylinder Thermocouple Locations 


\section{Temperature Measurements}

Type $\mathrm{S}(\mathrm{Pt}-10 \% \mathrm{Rh})-(\mathrm{Pt}-$ pure $)$ and type $\mathrm{B}(\mathrm{Pt}-30 \% \mathrm{Rh})-(\mathrm{Pt}-6 \% \mathrm{Rh})$ thermocouples, 10 -mil in diameter, were selected because they met the working temperature range of $70-2600^{\circ} \mathrm{F}$ with an accuracy of $\pm 1 \%$. The smaller the thermocouple diameter, the less will be the errors caused by heat conduction and radiation, and the less the temperature gradient on the porous material will be disturbed. However, the major problem with a small diameter bare thermocouple wire is it fails frequently when handling. Based on past experience with thermocouples, 10 -mil wire was a reasonable compromise.

After fabricating the thermocouples, they were cemented to the porous plate or cylinder with the Sauereisen cement. The lead wires passing up the furnace chimney were insulated with ceramic sleeving (391 Ultra Temp Ceramic Sleeving, Contronic Corp., Brooklyn, NY), rated for temperatures up to $3100^{\circ} \mathrm{F}$. The lead wires were then connected to ceramic-insulated connectors located in a cool region on top of the furnace. At the connectors, the lead thermocouple wires were changed to copper-compensating extension wire, having an accuracy of $\pm 2.0^{\circ} \mathrm{F}$, before electrical connections were made at the computer interface. The extension wires were matched to the type $\mathrm{S}$ or $\mathrm{B}$ thermocouple, thus reducing measurement errors.

To measure the surface temperature of the air cooler, the thermocouple junction was pounded into a hole (approximately 1/32-inch diameter) drilled into the outside surface of the air cooler (on the gas side). The thermocouple junction was positioned in the center of the heat-transfer chamber, opposite to an aspirated-thermocouple junction used to measure the gas temperature, as shown in Figures 5 and 6 for the plate and cylindrical geometry, respectively.

\section{EXPERIMENTAL RESULTS OF THE HEAT TRANSFER STUDY}

\section{Porous Plate}

Several plates were selected to investigate the effect of material of construction, porosities, and thicknesses on the heat transfer coefficients. In addition, for comparison, a nonporousfirebrick plate was used. The firebrick plate was open at the end $(0.5 \times 12.0$ inch slot), opposite to the combustion-gas entrance. The hot combustion gases then could flow down the heattransfer chamber, through the slot and up the chimney. For each experiment, the natural gas and combustion-air flowrates were held constant. Therefore, the air-fuel ratio, the combustion-gas temperature, and the heat-transfer chamber gas velocity were constant. The procedure adopted for each test was to run the furnace until reaching steady state, which took approximately one hour. After reaching steady state, all temperatures were measured and recorded by the data acquisition system.

The porous-plate temperature measurements are summarized in Table 1, and the location of all the thermocouples are shown previously in Figure 5. Table 1 shows that the retort-surface temperature (column 3) decreases with increasing cooling-air flowrates. The two bottom and one top porous-plate temperatures (columns 4 to 6 ) were relatively independent of the coolingair flowrate. The two temperatures at the bottom of the porous plate (columns 4 and 5) were approximately the same for each experiment conducted. 
Table 1. Summary of Heat Transfer Data for the Porous Plates

\begin{tabular}{|c|c|c|c|c|c|c|c|c|c|c|c|c|}
\hline 1 & 2 & 3 & 4 & 5 & 6 & 7 & 8 & 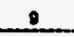 & 10 & 11 & 12 & 13 \\
\hline Nolotid & HT chmb & Retent & PP QL & $\begin{array}{l}\text { PPER } \\
\text { Tenge }\end{array}$ & PP Top & Akh & Ar out & AtAd & Qtume-nting & h. HTC & $\begin{array}{c}h . A C \\
\text { Btuhrat. }\end{array}$ & $u$ \\
\hline \multicolumn{13}{|c|}{$=665+1-15 \mathrm{SCH} F \mathrm{Q} 14.7 \mathrm{psin}, 60^{\circ} \mathrm{F}$} \\
\hline Fretrite & 1250 & 1150 & \multicolumn{2}{|c|}{1273} & 300 & $\infty$ & 715 & 400 & 9.054 & 65.8 & 11.9 & 10.1 \\
\hline $2 \pi M$ & 1463 & 1254 & 1050 & 1000 & 1500 & 70 & $\infty$ & 670 & 11,100 & 53.2 & 13.7 & 10.8 \\
\hline SKC-1Thick & 1520 & 1300 & 1576 & 1570 & 1100 & ro. & 908 & $\infty$ & 12,105 & 78.0 & 13.8 & 11.7 \\
\hline $\operatorname{sic} x$ thet & 1510 & 1307 & 1009 & 1523 & 100 & $\pi .0$ & 1099 & 500 & 12,470 & 61.5 & 15.6 & 12.5 \\
\hline PSZ & 1436 & 1279 & $\omega$ & 1520 & 1001 & $\pi 0$ & 253 & sts & 12,608 & 78.5 & 16.8 & 13.8 \\
\hline sxcturito & 1539 & 130 & 1672 & or & 1100 & 70.0 & 1026 & 500 & 13,841 & 726 & 17.3 & 14.0 \\
\hline \multicolumn{13}{|c|}{ Arfoul Ratio $=13.5-$ Cooling Ar Flow Rate $=605+15$ sCHF Q 14.7 psie, oof } \\
\hline Fubitet & 1791 & 1020 & \multicolumn{2}{|c|}{180} & Er & $\mathbf{6}$ & 1100 & $\mathbf{m}$ & 15,800 & Mes & 18.1 & 13.8 \\
\hline $\mathbf{Z M}$ & 2132 & 2000 & ח & 230 & 2108 & 418 & isol & 975 & 16,502 & 2033 & 152 & 14.3 \\
\hline sernith & $\mathbf{2 1 \pi}$ & 2000 & 20318 & 200 & 15 & ro. & 1530 & 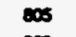 & 21,502 & 145.7 & 17.6 & 15.7 \\
\hline acer nutk & 200 & 2000 & 2000 & $m$ & 1500 & 700 & 1000 & $\infty$ & 23,a17 & 100.7 & 19.7 & 17.5 \\
\hline paz & 2000 & 1000 & $\omega$ & 2307 & 1500 & 80 & 104 & 807 & 22,100 & 210.4 & 20.0 & 182 \\
\hline \multirow{2}{*}{\multicolumn{13}{|c|}{ 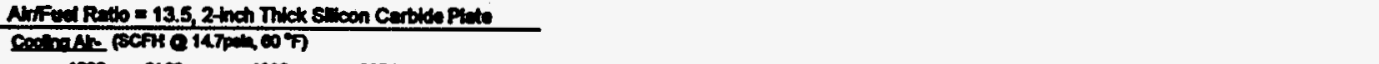 }} \\
\hline & & & & & & & & & & & & \\
\hline 1350 & 2100 & 1602 & 2034 & זים & 1501 & 70 & 1362 & 728 & 37,150 & 190.6 & 22.6 & 258 \\
\hline 170 & 2120 & 1000 & 2025 & $\omega$ & 1000 & 70 & 1200 & 697 & 27701 & 2045 & 33.4 & 207 \\
\hline 1000 & 2117 & 1000 & 2211 & 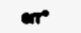 & 100 & 70 & $\$ 113$ & $\infty$ & 44672 & 2053 & 345 & 20.6 \\
\hline 2000 & 2006 & 1046 & 2168 & $\boldsymbol{\omega}$ & 190 & $\pi$ & $\infty 08$ & 500 & 4,355 & 2000 & 37.4 & 31.7 \\
\hline 2010 & 2001 & 2510 & 2187 & $\omega$ & 100 & 70 & 801 & 46 & 51,305 & 2012 & 30.5 & 324 \\
\hline
\end{tabular}

Table 2. Summary of Heat Transfer Data for the Porous Cylinder

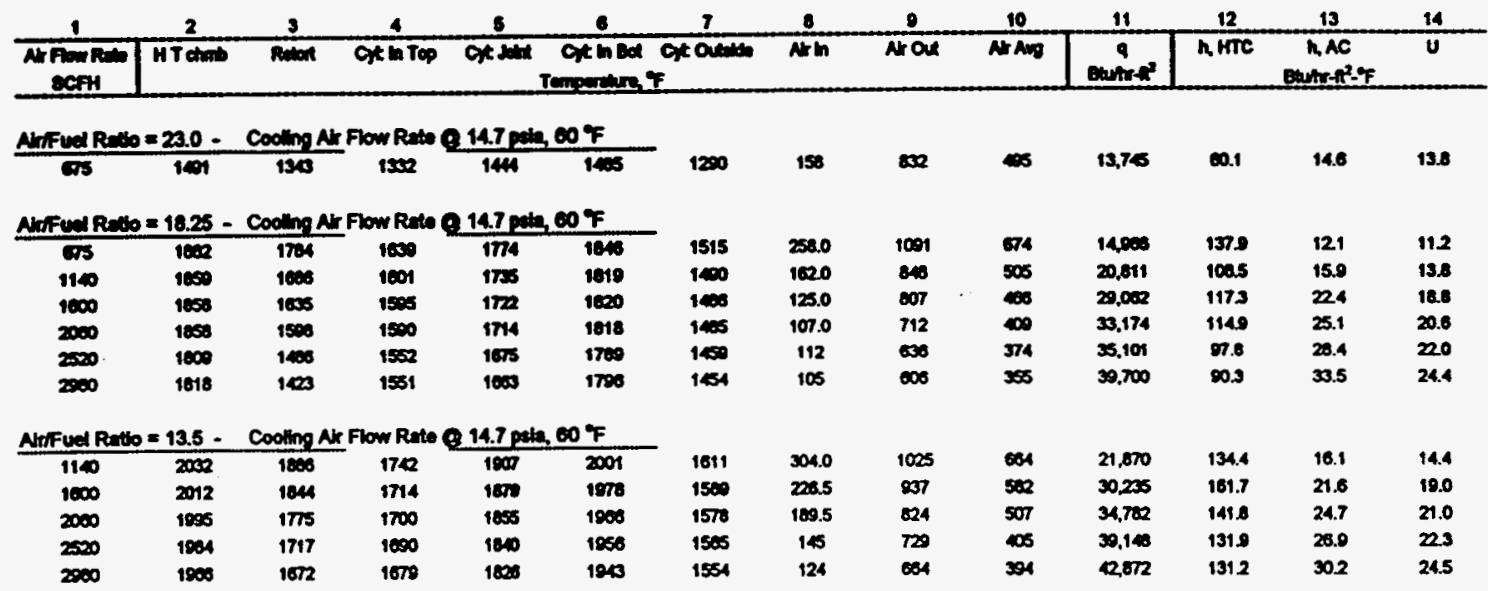


These data demonstrate the symmetry of the lateral-temperature profile on the porous plate. The gas temperatures, given in column 2 , are approximately equal to the temperatures at the bottom of the plate, given in columns 4 and 5 . The gas temperature should be greater than the temperature at the bottom of the plate to have heat transferred from the gas to the plate. At these high temperatures it is difficult to obtain completely accurate measurements.

The gas-side, air-side, and overall heat transfer coefficients are also summarized in Table 1 for air-fuel ratios of 13.5 and 23.0. The gas-side heat transfer coefficient (h, HTC) from column 11 in Table 4 is plotted in Figure 9. The air-side coefficient (h,AC) from column 12 in Figure 10. By comparing columns 11 and 12 , one can see that the heat-transfer rate is limited by the air-side heat transfer coefficient. As expected, when the cooling-air flowrate increased from 675 scfh to $3000 \mathrm{scfh}$, the air-side coefficient increased. This trend is shown in Figure 10 for all plates tested.

Figure 9 and Table 1 shows that SiC (2-inch thick) and PSZ have the highest gas-side heat transfer coefficients. When evaluating the overall effectiveness of the porous-plate material, however, mechanical strength must also be taken into account. Figures 9 and 10 shows that the PSZ had the best heat transfer coefficient, but the PSZ plate cracked after $14.0 \mathrm{hr}$ of operation. $\mathrm{SiC}$ was also chosen for the cylindrical furnace because it is a common material. Most ceramic manufacturers in the United States produce $\mathrm{SiC}$.

Because of PSZ's high heat transfer coefficients, vendors were contacted to see if a strong PSZ material could be found. The Selee Corp. (Hendersonville, NC) manufactures a PSZ material that is stronger than $\mathrm{SiC}$. This material should be tested in future research.

At gas inlet temperatures of $1600^{\circ} \mathrm{F}$, the gas side heat transfer coefficients are $54 \mathrm{BTU} / \mathrm{hr}$ $\mathrm{ff}^{2 \circ} \mathrm{F}$ and $56 \mathrm{BTU} / \mathrm{hr} \mathrm{ft}^{2 \circ} \mathrm{F}$ for the mullite and zirconia porous plates, respectively, compared with $20 \mathrm{BTU} / \mathrm{hr} \mathrm{ft}^{2 \circ} \mathrm{F}$ for the reference plate.

At gas inlet temperatures of $2350^{\circ} \mathrm{F}$, the gas side heat transfer coefficients are $180 \mathrm{BTU} / \mathrm{hr}$ $\mathrm{ft}^{2 \circ} \mathrm{F}$ and $240 \mathrm{BTU} / \mathrm{hr} \mathrm{ft}^{2 \circ} \mathrm{F}$ for the mullite and zirconia porous plates, respectively, compared with $100 \mathrm{BTU} / \mathrm{hr} \mathrm{ft}^{2} \mathrm{~F}$ for the reference plate.

\section{Porous Cylinder}

The temperature measurements for the cylindrical heat-transfer chamber are summarized in Table 2, and the location of all the thermocouples are shown previously in Figure 6. Only a SiC (silica bonded) cylinder could be tested because of time constraints.

The gas-side, air-side, and overall heat transfer coefficients are summarized in Table 2 (columns 12 to 14) for air-fuel ratios of 13.5, 18.25, and 23.0. The gas-side heat transfer coefficient (h, HTC) from column 12 in Table 2 is plotted in Figure 11. The air-side coefficient $(\mathrm{h}, \mathrm{AC})$ from column 13 in Figure 12. Figures show similar trends to those observed in the porous-plate study. 


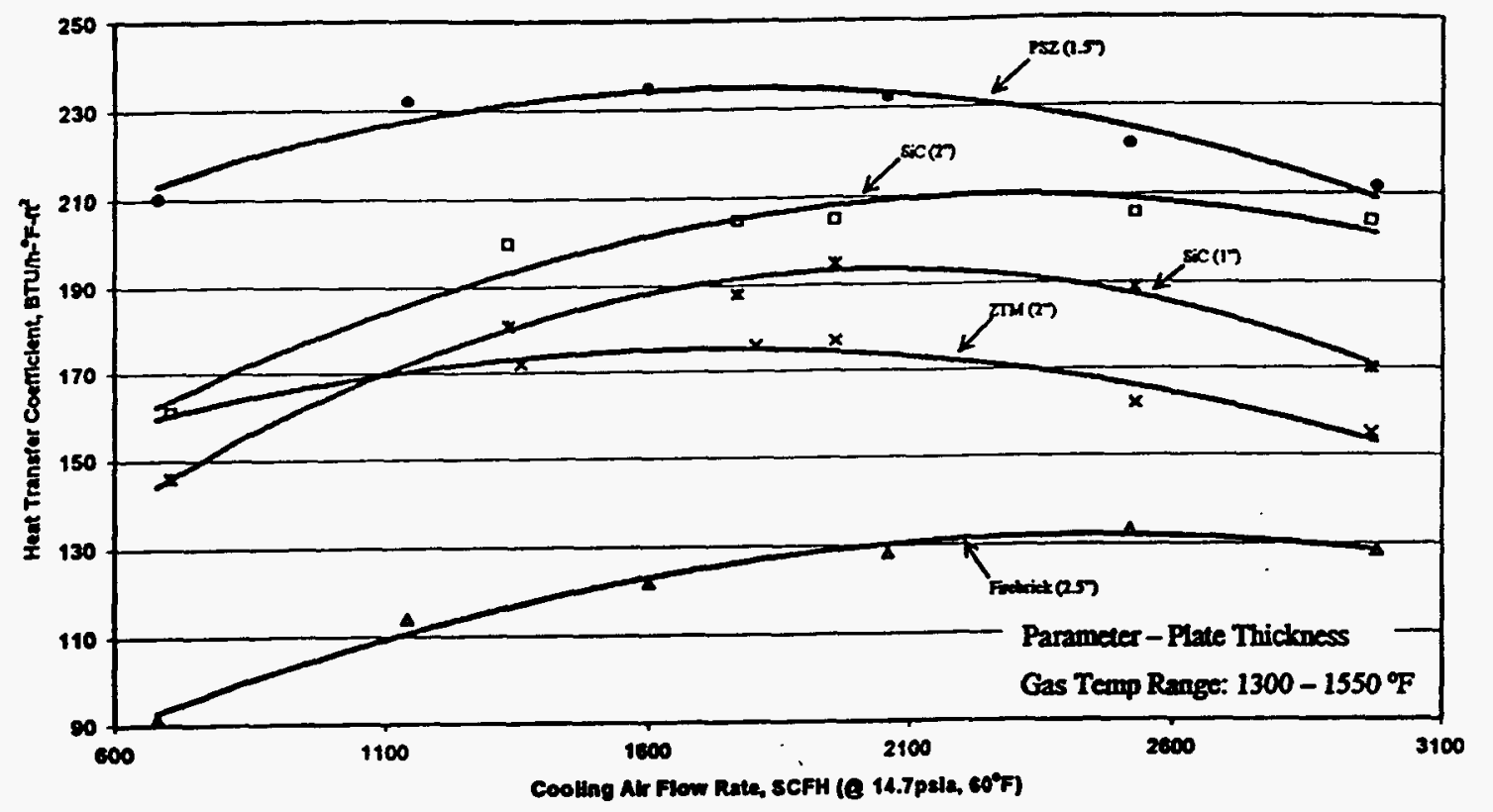

Figure 9. Comparison of the Gas-Side Heat Transfer Coefficients for the Porous Plates

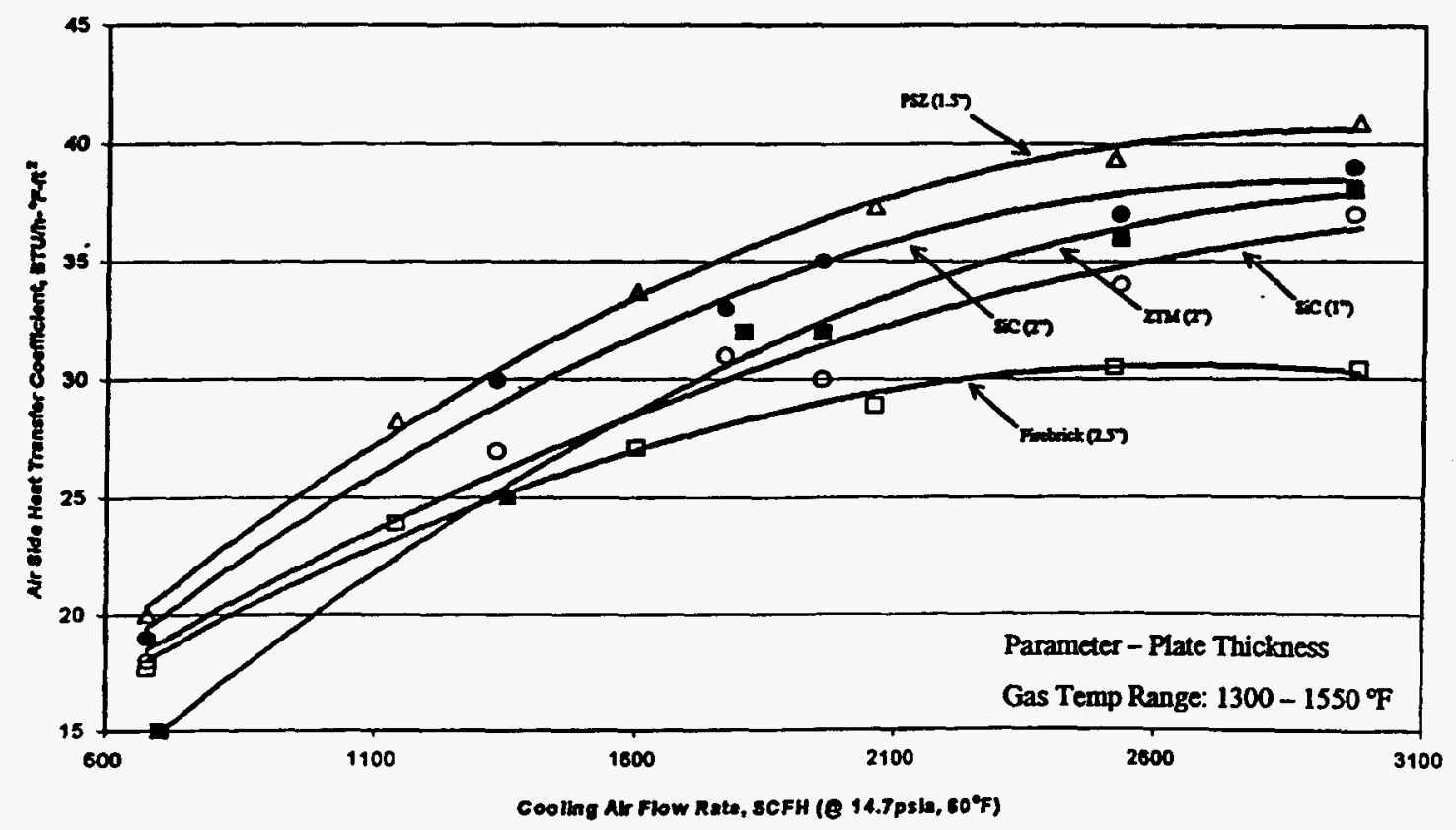

Figure 10. Comparison of the Air-Side Heat Transfer Coefficients for the Porous Plates 


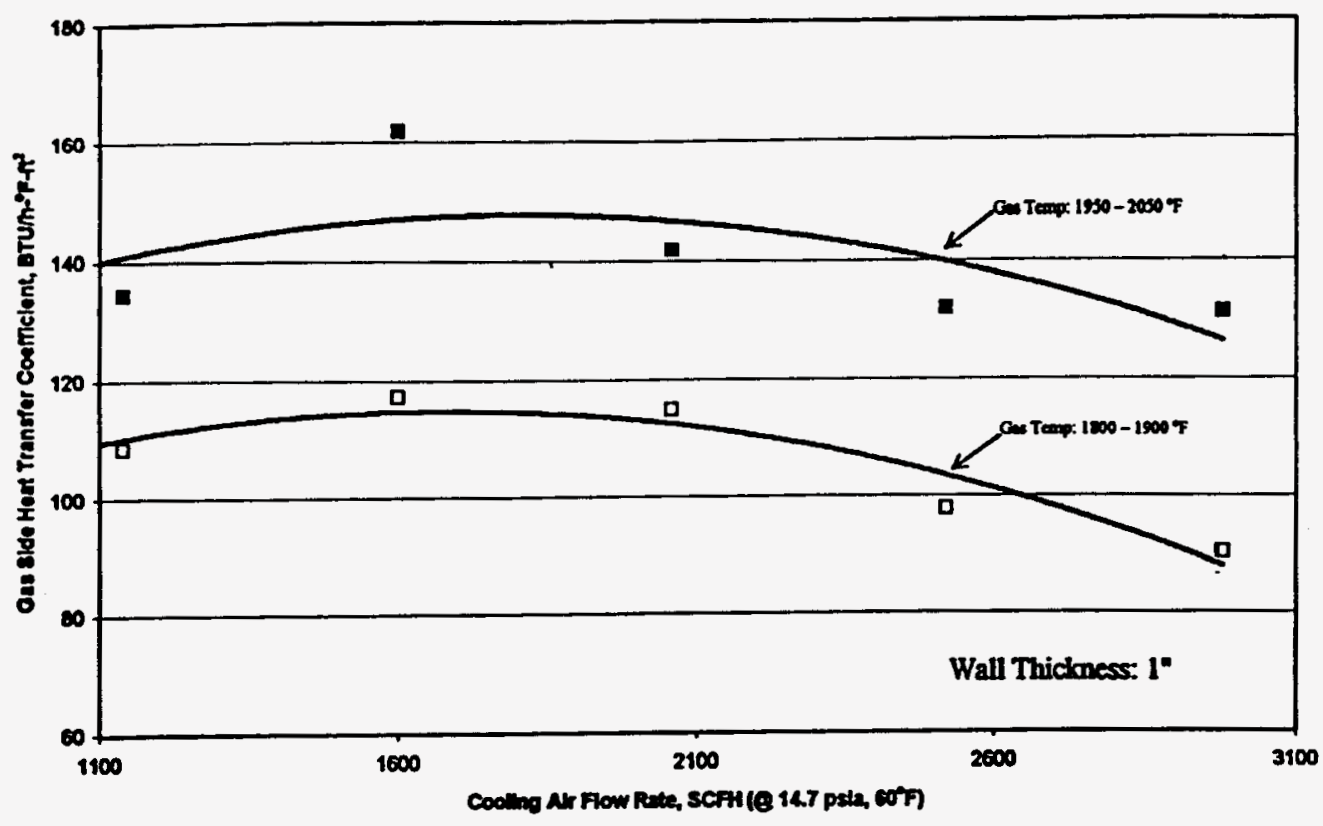

Figure 11. Effect of Gas Temperature on the Gas-Side Heat Transfer Coefficients for the Porous SiC Cylinder

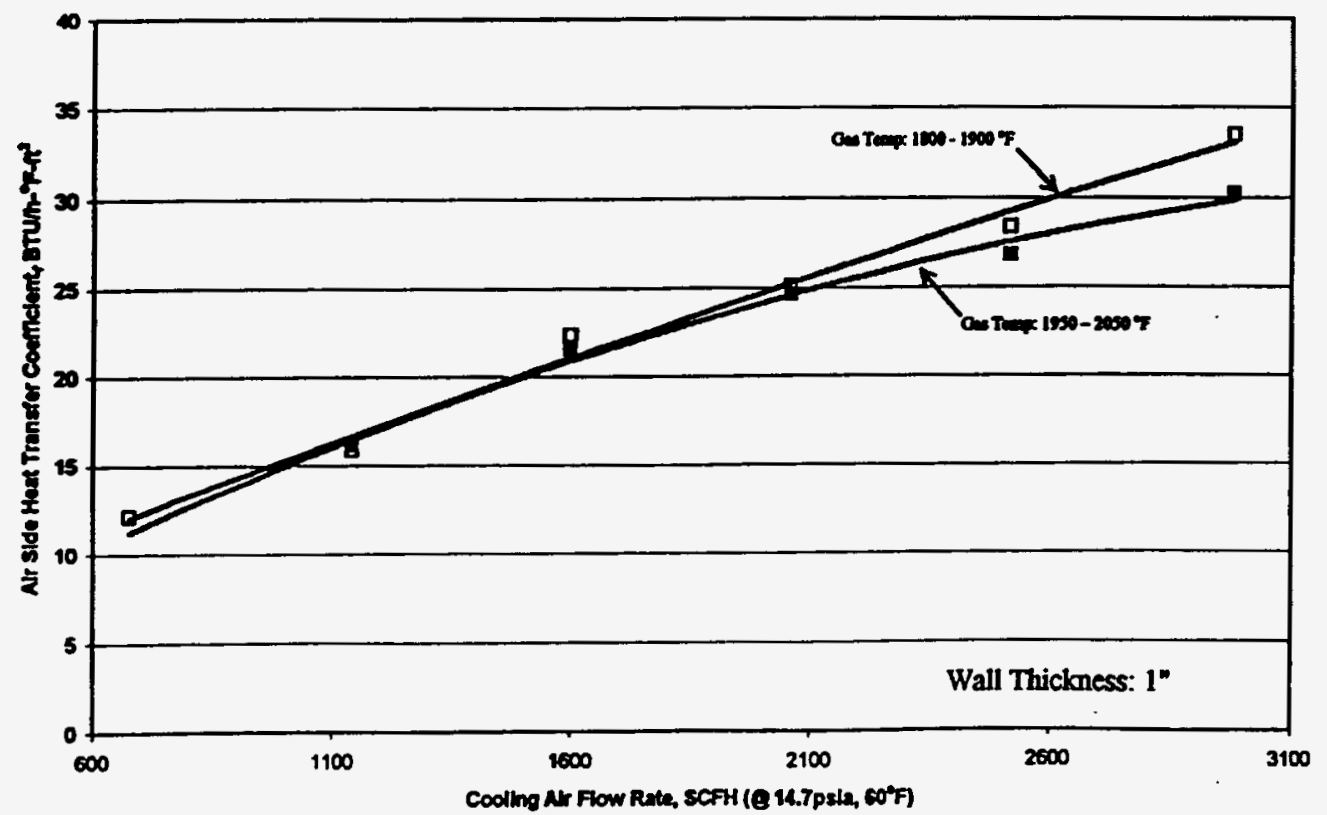

Figure 12. Effect of Gas Temperature on the Air-Side Heat Transfer Coefficients for the Porous SiC Cylinder 
Figure 11 shows that the gas-side heat transfer coefficient increases, reaches a maximum and then decreases as the cooling-air flowrate increases. Again, as was the case for the porous-plate tests, it is not clear why this occurred. Column 12 through 14 in Table 2 show that the heattransfer rate is limited by the air-side heat transfer coefficient. As expected, Figure 11 shows that when the cooling-air flowrate is increased from $675 \mathrm{scfh}$ to $3000 \mathrm{scfh}$, the air-side coefficient increased. This trend was also observed in the porous-plate study.

Although the heat transfer coefficients measured for the porous cylinder (Table 2, columns 12 to 14) were lower than those of the porous plate (Table 1, columns 12 to 14), they are still very promising. The porous cylinder and plate furnaces have significantly higher heat transfer coefficients than conventional gas-fired furnace, specially in high temperature range. This is expected because at low temperatures convective heat transfer dominates and at high temperatures radiative heat transfer dominates. The porous wall increases the radiative component of heat transfer.

\section{CONCLUSION AND RECOMMENDATION}

The heat transfer study has demonstrated experimentally that the heat transfer capacity of the radiant porous wall mantle is high relative to heat transfer rates typically observed in conventional gas-fired furnaces, which is in the range of 5 to $15 \mathrm{BTU} / \mathrm{hr} \mathrm{ft}^{2 \circ} \mathrm{F}$. The high performance was particularly very impressive in the mantle annulus temperature range of $1700^{\circ} \mathrm{F}$ to $2350^{\circ} \mathrm{F}$.

The experimentation performed to date also confirmed the predictions of the computer model of the porous wall radiation mantle.

Since the mechanical performance of the porous wall material is an important element in the overall performance, it was concluded that the next step of the program should not only include further evaluation of candidate porous wall materials from a heat transfer point of view, but also from a structural and maintenance point of view.

\section{CURRENT STATUS OF THE PROGRAM}

Following the experimental program which confirmed the potential of the radiant porous wall concept to achieve a major increase in gas fired heating mantle capacity, Procedyne proposed and received a development contract from the Department of Energy to engineer, fabricate, install, and demonstrate a commercial retort furnace based on this concept.

This effort is in progress with the engineering, manufacturing, and installation of the commercial furnace completed. The commissioning of this prototype unit is anticipated to be completed in September 2002. Detailed evaluation and field-test operation will then be started. The program is expected to be completed by June 2003. 


\section{ACKNOWLEDGMENTS}

The research efforts on this project were financed in part by the following industrial and governmental agencies:

(1) Phase I grant from Gas Technology Institute (formerly known as Gas Research Institute) of Chicago, Illinois.

(2) Phase II grant from Gas Technology Institute, Chicago, Illinois.

(3) Grant from the New Jersey Commission on Science and Technology, Trenton, New Jersey under Merit Based Technology Transfer Program.

(4) Prototype development grant from the Department of Energy, Golden, Colorado under Invention and Innovation Program.

\section{REFERENCES}

1. Silla, H., Shroff, V.C., Porous Plate Radiation Heat Transfer Study, Stevens Institute of Technology, Hoboken, NJ, February 1991.

2. Echigo, R., "Effective Energy Conversion Method Between Gas Enthalpy and Thermal Radiation and Application to Industrial Furnaces", $7^{\text {th }}$ International Heat Transfer Conference, Munchen, Vol. 6, pp. 361-366, 1982.

3. Kennedy, L.A., and Ettefagh, "Passing Combustion Gases Through Multilayered Porous Surfaces to Enhance Radiative Heating", ASMEJJSME Thermal Engineering Proceedings, Vol. 5, pp. 189-195, 1991.

4. Zaveri, S., Determining Gas Temperature Using an Aspirated Shielded Thermocouple, Stevens Institute of Technology - A Thesis, Hoboken, NJ, May 1993.

5. Reed, R.J., (Ed), North American Combustion Handbook, North American Manufacturing Co., Cleveland, $\mathrm{OH}, 1978$.

6. Bird, R.B., Stewart, W.E., Lightfoot, E.N., Transport Phenomena, John Wiley and Sons, New York, NY, 1960.

7. Brown, R.W., "Taking the Black Magic Out of High Temperature Nonmetallics", Chem. Eng., April 21, 1958. 


\section{APPENDIX IV}

\section{Engineering Drawings}

1. D-17679 Rev D. Shell Assembly HT - 2050-1024 Gas Fired

2. D - 17664 Rev. C Porous Wall Heating Mantle Assembly HT - 2050 - 1024 Gas Fired 


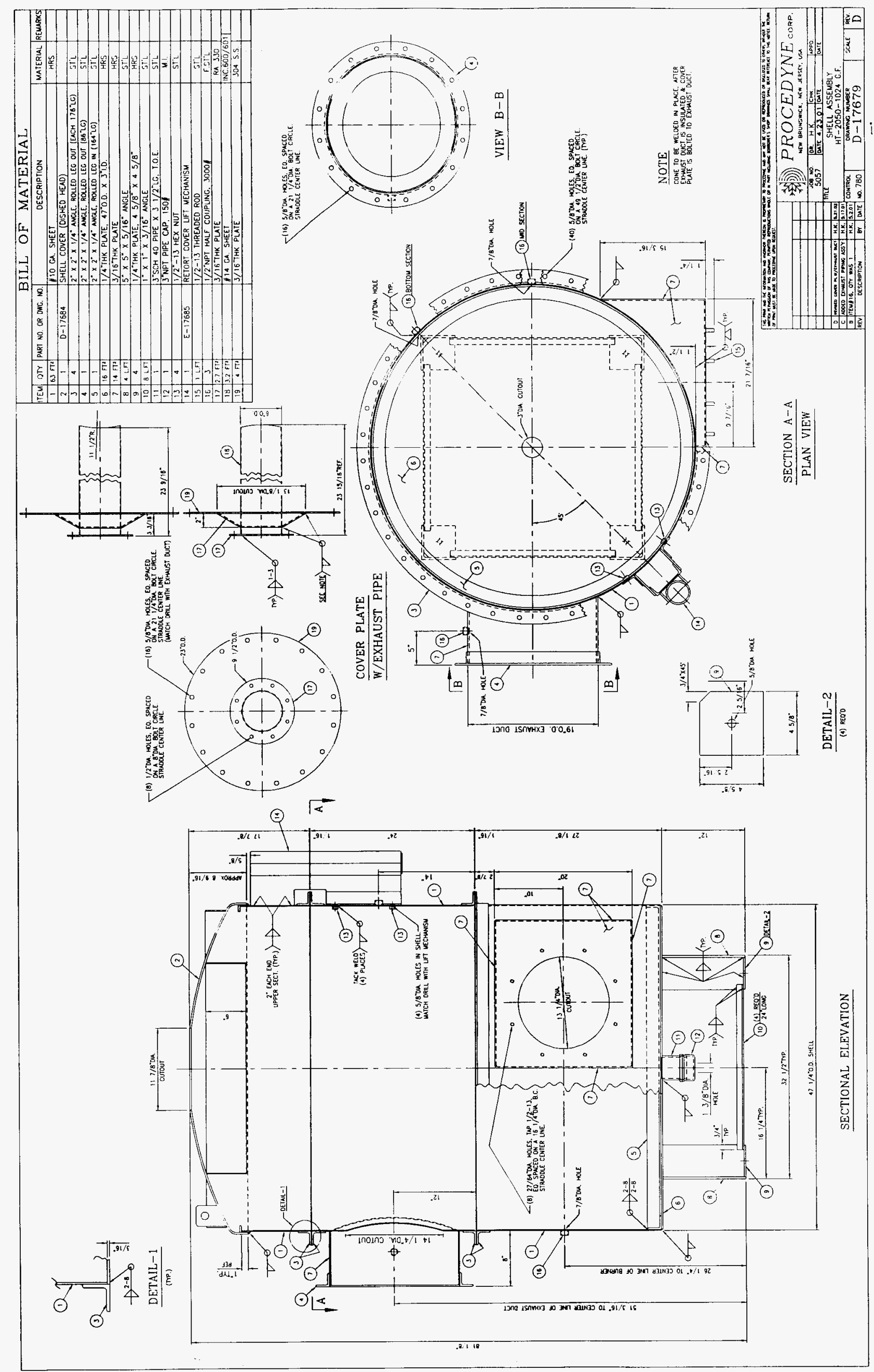




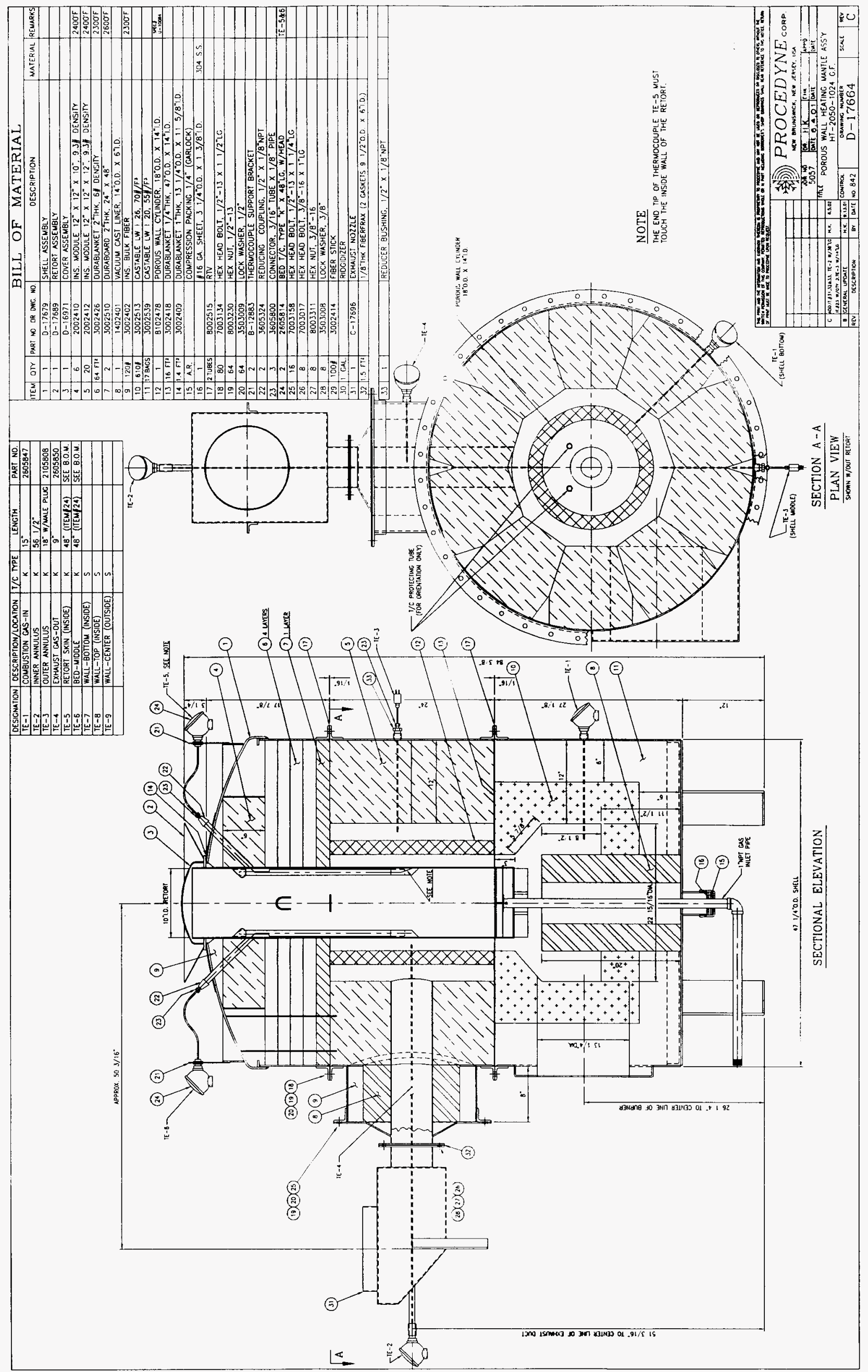

